\title{
Welding of Magnesium Alloys
}

\author{
Parviz Asadi, Kamel Kazemi-Choobi and Amin Elhami
}

Additional information is available at the end of the chapter

http://dx.doi.org/10.5772/47849

\section{Introduction}

Magnesium is the sixth most abundant element on the Earth's surface, with virtually inexhaustible supplies in the oceans. It is the third most plentiful element dissolved in seawater, with an approximate concentration of $0.14 \%$ (Busk, 1987). Over recent years the industrial output of magnesium alloys has been rising by almost $20 \%$ per annum. Magnesium and its alloys, as the lightest structural material, are about $40 \%$ lighter than aluminium and as much as about $78 \%$ lighter than steel. It is demonstrated that using magnesium alloys results in a $22-70 \%$ weight reduction, compared to using alternative materials (Kulekci, 2008). Magnesium alloys have excellent specific strength, excellent sound damping capabilities, good cast-ability, hot formability, excellent machinability, good electromagnetic interference shielding, and recyclability (Haferkamp et al., 2000), (Mordike and Ebert, 2001), (Pastor et al., 2000). Moreover, magnesium ignites with difficulty in air due to its high heat capacity. Some disadvantages of magnesium are presented based on the following, Low elastic modulus; High degree of shrinkage on solidification; High chemical reactivity. Additionally, these alloys have limited fatigue and creep resistance at elevated temperatures (Mordike and Ebert, 2001). Because of the hexagonal close-packed (HCP) crystal structure, magnesium alloys also have a limited ductility and cold workability at room temperature (Sanders et al., 1999). These alloys have about the same corrosion resistance in common environments as mild steel, but are less corrosion resistant than aluminium alloys (Busk, 1987). Thus, magnesium alloy usage has been limited due to its poor corrosion resistance and low ductility. In order to overcome these problems, new alloys, such as Mg-AZ91D, have been developed and have improved corrosion resistance (Munitz et al., 2001). The property profiles demanded by automobile and other large-scale potential users of magnesium have revealed the need for alloy development. Fig. 1 illustrates the different trends in alloy development depending on the main requirement. The major alloying elements are aluminium, zinc, thorium and rare earths. Aluminium is the most important alloying element in the ternary $\mathrm{Mg}-\mathrm{Al}$ series, which comprises $\mathrm{AZ}(\mathrm{Mg}-\mathrm{Al}-\mathrm{Zn}), \mathrm{AM}(\mathrm{Mg}-\mathrm{Al}-\mathrm{Mn})$ and $\mathrm{AS}(\mathrm{Mg}-\mathrm{Al}-\mathrm{Si})$ al- 
loys. There are two binary systems employing manganese and zirconium (Oates, 1996). It is also common to classify magnesium alloys into those for room and elevated temperature applications. Rare earth metals and thorium are the main alloying elements for high temperature alloys. Aluminium and zinc, added either singly or in combination, are the most common alloying elements for room temperature applications because at elevated temperatures the tensile and creep properties degrade rapidly (Marya et al. 2000).

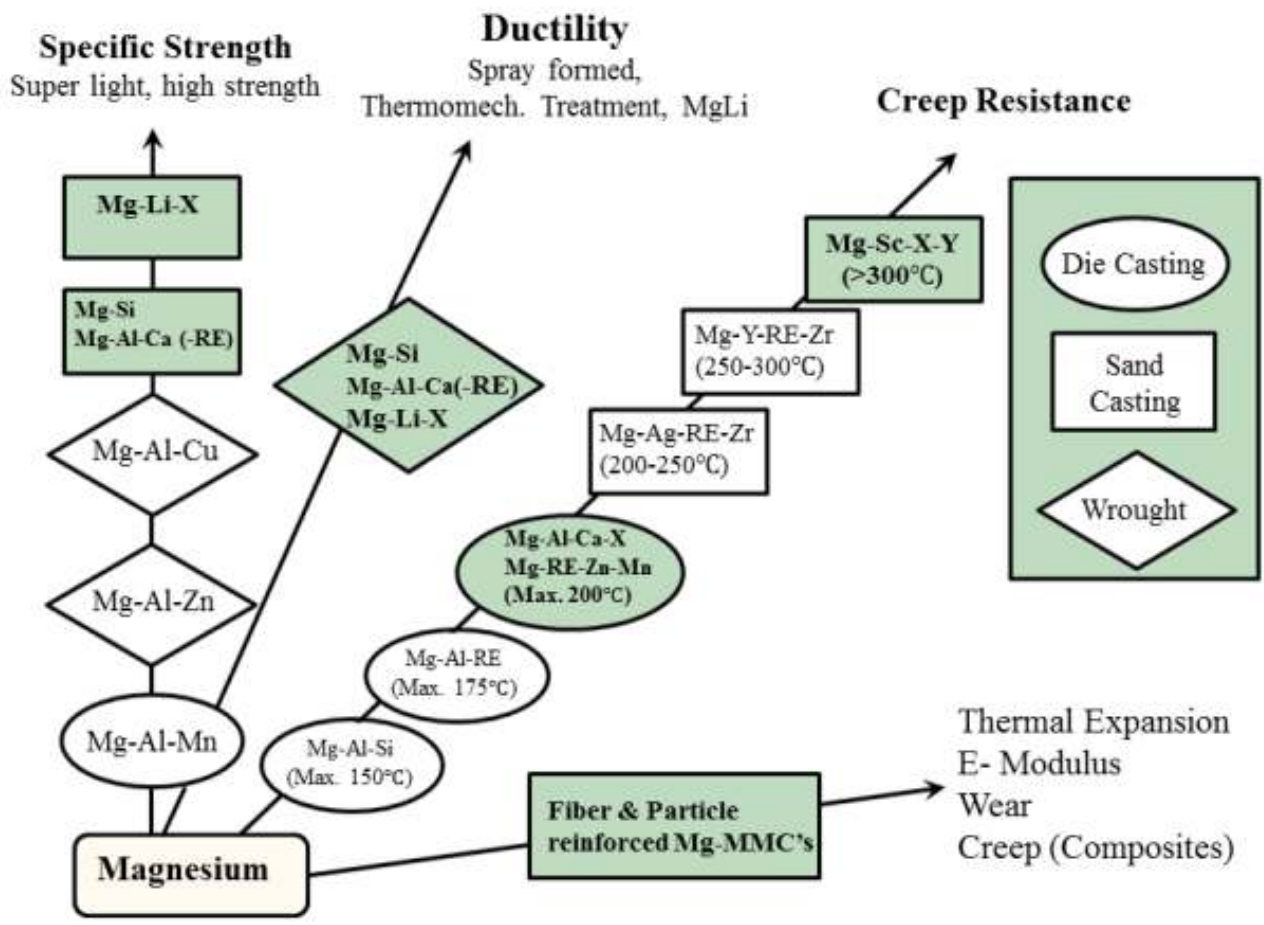

Figure 1. Directions of alloy development (Mordike and Ebert, 2001).

To date, no international code for designating magnesium alloys exists but the method used by the American Society for Testing Materials (ASTM) has been widely adopted. In this system, the first two letters indicate the principal alloying elements according to the following codes: A, aluminium; B, bismuth; C, copper; D, cadmium; E, rare earths; F, iron; G, magnesium; $\mathrm{H}$, thorium; $\mathrm{K}$, zirconium; $\mathrm{L}$, lithium; $\mathrm{M}$, manganese; $\mathrm{N}$, nickel; $\mathrm{P}$, lead; $\mathrm{Q}$, silver; $\mathrm{R}$, chromium; S, silicon; T, tin; $\mathrm{W}$, yttrium; $\mathrm{Y}$, antimony and $\mathrm{Z}$, zinc. The two or one letter is followed by numbers which represent the nominal compositions of these principal alloying elements in weight percentage, rounded off to the nearest whole number. For example, AZ91 indicates the alloy $\mathrm{Mg}-9 \mathrm{Al}-1 \mathrm{Zn}$ with the actual composition ranges being 8.3-9.7 $\mathrm{Al}$ and 0.4-1.0 Zn. Suffix letters A, B, C, etc. refer to variations in composition within the specified range and $\mathrm{X}$ indicates that the alloy is experimental. Despite the good castability of some mentioned alloys (such as Mg-AZ91D alloys), it is not always possible or economically 
favourable to cast complex magnesium parts. Joining of magnesium parts, which may be crucial for these applications, is still restricted. It is, thus, very desirable that joining technologies be developed and made accessible for industrial applications (American Society of Metals [ASM], 1990).

Welding and joining processes are essential for the development of practically every manufactured product. However, these processes often appear to consume greater fractions of the product cost and to create more of the production difficulties than might be expected (ASM, 1993). There are a number of reasons that explain this situation. Because there are many fusion welding processes, one of the greatest difficulties for the manufacturing engineer is to define which process will produce satisfactory properties at the lowest cost. There are no simple answers. Any change in the part geometry, material, value of the end product, or size of the production run, as well as the availability of joining equipment, can influence the choice of joining method. For small lots of complex parts, fastening may be preferable to welding, whereas for long production runs, welds can be stronger and less expensive.

To date magnesium alloys have not usually been welded except for some repaired structures because of the occurrence of defects such as oxide films, cracks, and cavities (Haferkamp et al., 2000). However, the broader application of magnesium alloys requires reliable welding processes. Magnesium alloy components may be joined using mechanical clasps as well as a variation of welding methods including tungsten arc inert gas (TIG), plasma arc welding, electron beam welding (EBW), laser beam welding (LBW), friction stir welding (FSW), explosion, electromagnetic welding, ultrasonic welding, and resistance spot welding (RSW).

\section{Laser beam welding}

Laser beam welding (LBW) uses a moving high-density (105 to $107 \mathrm{~W} / \mathrm{cm} 2$ ) coherent optical energy source called a laser as the source of heat. "Laser" is an acronym for "light amplification by stimulated emission of radiation." The coherent nature of the laser beam allows it to be focused to a small spot, leading to high energy densities (ASM, 1993). Fig. 2 illustrates the schematic of the laser beam welding.

Advantages and Limitations of LBW are listed below (ASM, 1993):

- $\quad$ Light is inertialess (hence, high processing speeds with very rapid stopping and starting become possible).

- Focused laser light provides high energy density.

- Laser welding can be used at room atmosphere.

- Difficult to weld materials (such as titanium, quartz and etc) can be joined.

- Workpieces do not need to be rigidly held.

- No electrode or filler materials are required.

- Narrow welds can be made.

- Precise welds (relative to position, diameter, and penetration) can be obtained.

- Welds with little or no contamination can be produced. 
- $\quad$ The heat affected zone (HAZ) adjacent to the weld is very narrow.

- Intricate shapes can be cut or welded at high speed using automatically controlled light deflection techniques.

- The laser beam can also be time shared.

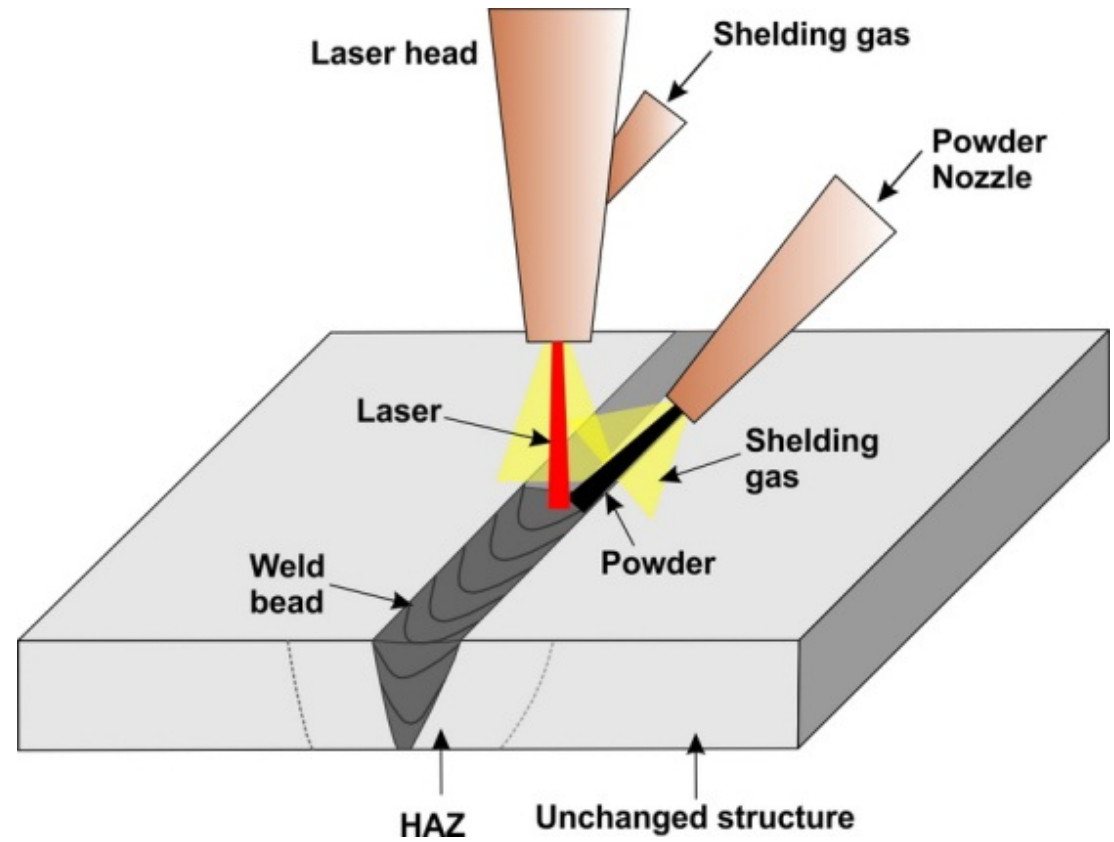

Figure 2. The schematic view of LBW process.

In the last two decades, the manufacturing industry has been actively engaged in qualifying laser welding, because high strength joints with low levels of residual stress and high visual quality can be achieved with this joining process. The effectiveness of laser welding depends greatly on the physical properties of the material to be welded. Magnesium alloys possess certain inherent characteristics such as low absorptivity of laser beams, strong tendency to oxidize, high thermal conductivity, high coefficient of thermal expansion, low melting and boiling temperatures, wide solidification temperature range, high solidification shrinkage, form low melting point constituents, low viscosity, low surface tensions, high solubility for hydrogen in the liquid state, and absence of colour change at the melting point temperature. Therefore, some processing problems and weld defects can be observed in laser welding of magnesium alloys such as unstable weld pool, substantial spatter (Haferkamp et al., 2001), strong tendency to drop through for large weld pools, sag of the weld pool (especially for thick workpiece), undercut (Lehner and Reinhart, 1999), porous oxide inclusions, loss of alloying elements, excessive pore formation (particularly for die castings) (Zhao and DebRoy, 2001), liquation and solidification cracking (Marya and Edwards, 2000). Despite the mentioned problems, among the welding technologies, laser welding has been considered to 
be an attractive and preferred fusion process due to high welding speed, very narrow joints with smaller heat affected zone (HAZ) because of using shielding gases, low distortion and excellent environment adaptability (Wang et al., 2001).

\section{1. $\mathrm{CO}_{2}$ and $\mathrm{Nd}: \mathrm{YAG}$ lasers}

Lasers have been promoted as potentially useful welding tools for a variety of applications. Two main types of lasers, $\mathrm{CO}_{2}$ and Nd:YAG with wave lengths of 10.6 and $1.06 \mu \mathrm{m}$, respectively, have been used to investigate the weldability of magnesium alloys. The availability of high-power continuous-wave $(\mathrm{CW})$ carbon dioxide $\left(\mathrm{CO}_{2}\right)$ and neodymium-doped yttrium aluminium garnet (Nd:YAG) lasers and the limitations of current welding technology have promoted interest in deep-penetration welding in the past twenty years using these devices. The $\mathrm{CO}_{2}$ laser has high power output, high efficiency, proven reliability and safety. The weldability of magnesium alloys was reported to be significantly better with the Nd:YAG laser due to its shorter wave length. Leong investigated welding AZ31 alloy using both $\mathrm{CO}_{2}$ and pulsed Nd:YAG laser, and illustrated the difficulties of $\mathrm{CO}_{2}$ welding. He concluded that Nd:YAG laser was more suitable for magnesium alloy welding (Leong, 1998).

\subsection{Laser power}

The penetration depth with laser welding is directly related to the power density of the laser beam and is a function of incident beam power and beam diameter. For a constant beam diameter, penetration typically increases as the beam power is increased. It is well known that high power density at the workpiece is crucial to obtain keyhole welding and to control the formation of welds. The effect of laser power on the penetration depth and weld width for WE43 alloy welded at a speed of $33 \mathrm{~mm} / \mathrm{s}$ and a focused diameter of $0.25 \mathrm{~mm}$ are shown in Fig. 3a and 3b, respectively (Dhahri et al., 2001). Fig. 3 also clearly shows that the threshold power for deep penetration mode welding of cast WE43 alloy is approximately $1 \mathrm{~kW}$ for a $\mathrm{CO}_{2}$ laser.
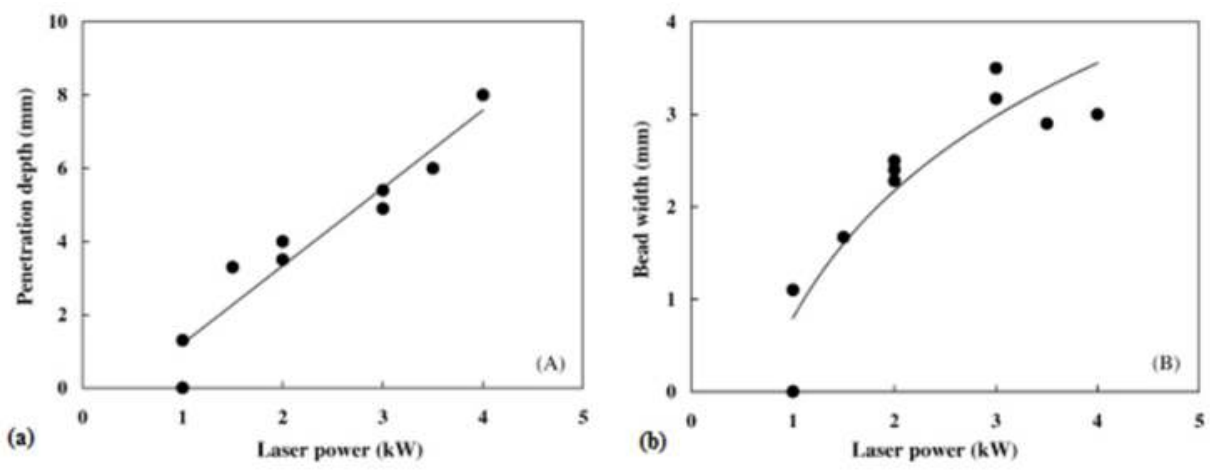

Figure 3. Effect of $\mathrm{CO}_{2}$ laser power on (a) penetration depth, and (b) bead width of cast WE43 alloy joints (Dhahri et al., 2001). 
High beam powers led to deep and wide beads, and reduce both ripples and crowning. Lower irradiance incident upon the workpiece would reduce the spatter as well as the loss of high vapour pressure constituents. It is reported that lower power level and slower speed lead to better weld quality (Cao et al., 2006). A loss of tensile strength was found with Nd:YAG laser power lower than 2kW (Lehner and Reinhart, 1999). For ZE41A-T5 sand castings keyhole welding is reached at a threshold irradiance of $1.5 \times 106 \mathrm{~W} / \mathrm{cm} 2$ for the machined surface conditions using $2.5 \mathrm{~kW}$ Nd:YAG laser power, but the keyhole mode is obtained at $4.0 \times 105 \mathrm{~W} / \mathrm{cm}^{2}$ for the as-cast surface conditions (Cao et al., 2005). It can be concluded that the as-cast surface requires slower power density for the formation of keyholes indicating that the as-cast surfaces have higher energy absorptivity for Nd:YAG laser beams probably due to the coarser surface conditions.

\subsection{Welding speed}

The effects of welding speed on penetration depth and weld width at different levels of power for $\mathrm{CO}_{2}$ and $\mathrm{Nd}$ :YAG lasers are shown in Fig. 4. It can be seen that the penetration depth and weld width both decrease linearly with increasing welding speed.
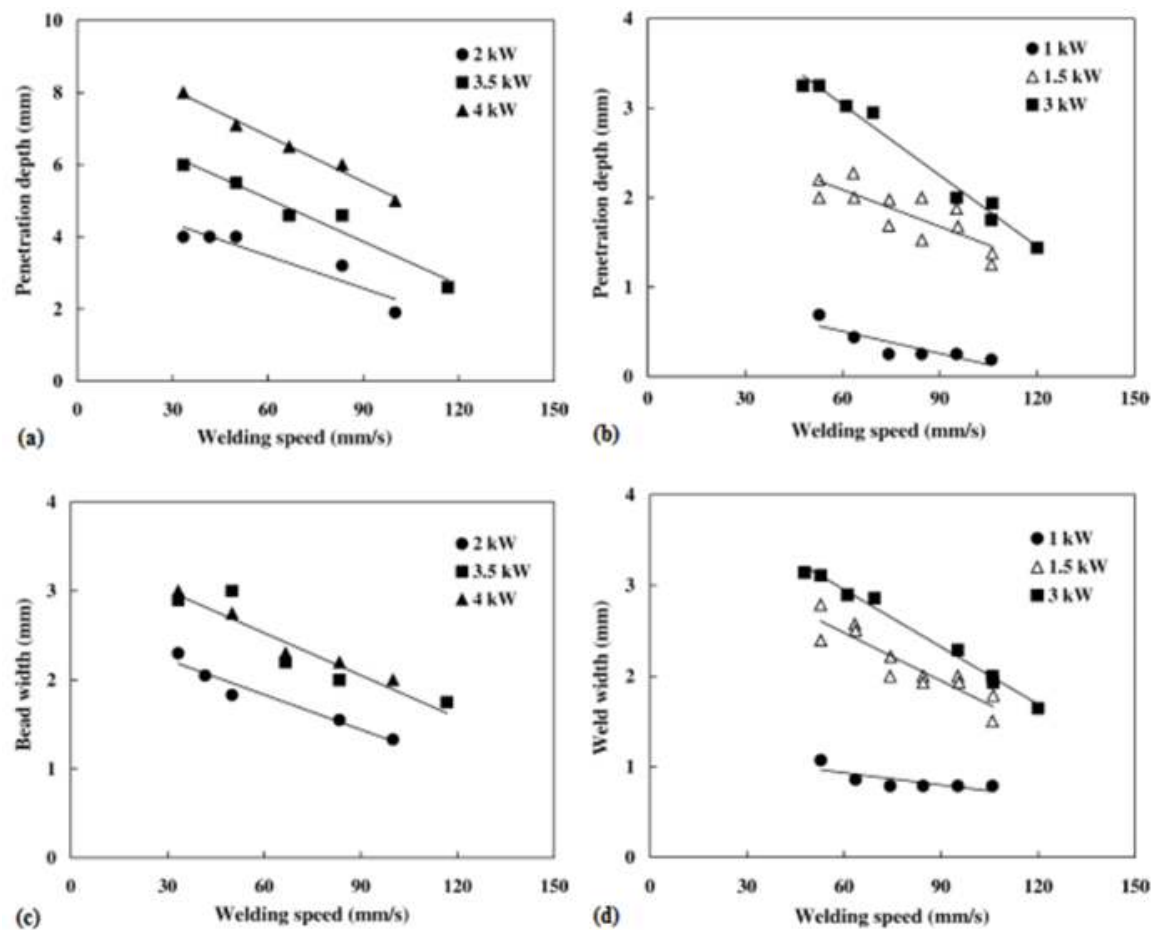

Figure 4. Effect of welding speed on penetration depth for (a) cast WE43 alloy joints welded using a $\mathrm{CO}_{2}$ laser and (b) die-cast AM60B alloy joints welded using a Nd:YAG laser as well as the effect of welding speed on weld width for (c) cast WE43 alloy joints welded using a $\mathrm{CO}_{2}$ laser and (d) die-cast AM60B alloy joints welded using a Nd:YAG laser (Marya and Edwards, 2001). 
It is well known that a further decrease in welding speed led to little increase in penetration depth but there are increases in weld and HAZ widths (Dhahri et al., 2000). High welding speed was reported to reduce ripples but greatly increase crowning, or even to increase tendency to brittleness in the fusion zone (Cao et al., 2006).

Fig. 5 indicates the effect of welding speed on the penetration depth as well as on the area of molten weld pool for wrought AZ21A and die-cast AZ91D alloys welded using a $1.7 \mathrm{~kW}$ CW Nd:YAG laser (Marya and Edwards, 2001). Though similar welding parameters are used, various magnesium alloys exhibit different welding performance due to their different thermo-physical properties.

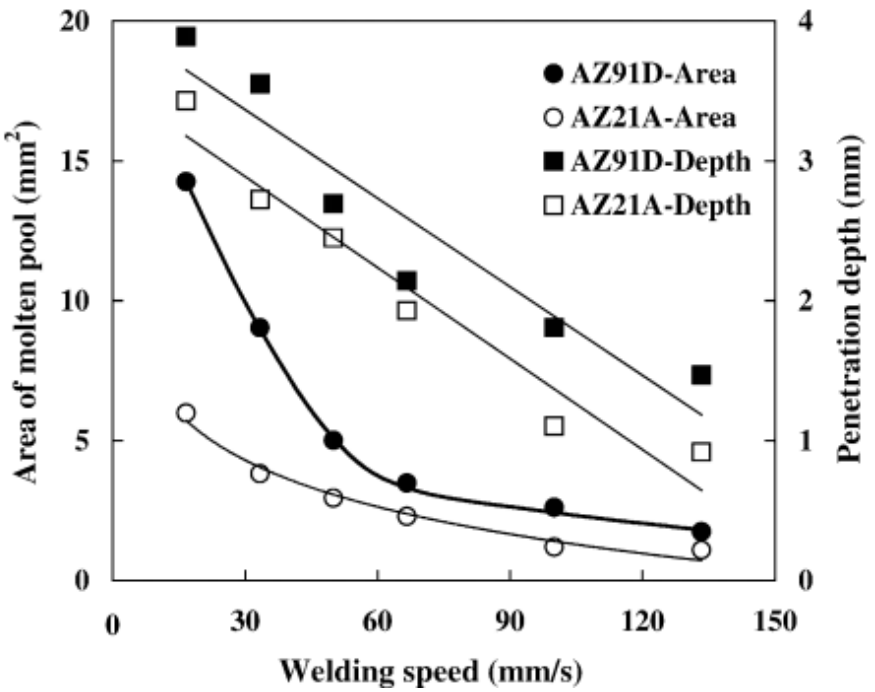

Figure 5. Area of molten weld pool and penetration depth versus welding speed for AZ21A and AZ91D alloys using a 1.7 kW CW Nd:YAG laser (Marya and Edwards, 2001).

Die-cast AZ91D has a lower thermal conductivity of $51 \mathrm{~W} / \mathrm{mK}$ as compared with $139 \mathrm{~W} / \mathrm{mK}$ for wrought AZ21A alloy. Thus, the AZ91D alloy has a higher weld depth and weld volume compared with AZ21A alloy. Because of the difference in their thermal properties, much more studies, therefore, is needed to systematically investigate the laser welding characteristics of different magnesium alloys.

When the laser energy input was more than that required for a full penetration, large holes or weld dropout could be observed. Weld drop was observed in both $\mathrm{CO}_{2}$ and diode conduction welding. This could be due to the long interaction time or the higher power density, while the low viscosity liquid is not able to sustain the welding pool. This defect would significantly reduce the load capability of the weld. Fig. 6 is an example of a $\mathrm{CO}_{2}$ weld drop. The energy input could be controlled by controlling the welding speed to avoid overmelting, and hence large hole formation and weld dropout (Zhu et al., 2005). 


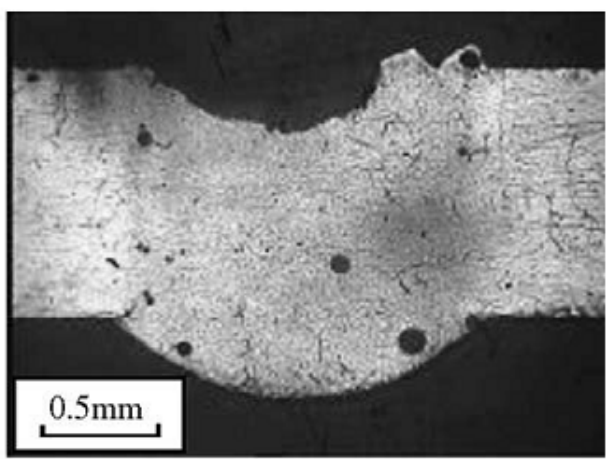

Figure 6. Weld dropout defect in laser welding of AZ31 (Zhu et al., 2005).

It may be proposed whether crowning, ripples, and weld cross-section morphology can be related. It was found high beam powers reduce both ripples and crowning. High welding speeds although reduces ripples, greatly increases crowning. It is clear that these two phenomena are independent. The ripple phenomenon has been associated with growth rate fluctuations due to the effects of surface tension of the weld pool during solidification. Fig. 7 shows the crown increased rapidly with increasing the welding speed and decreasing the beam power. The phenomenon of crowning was found to be primarily dependent upon the welding speed. Large welding speed and low beam powers promote the crowning (Marya and Edwards, 2001).
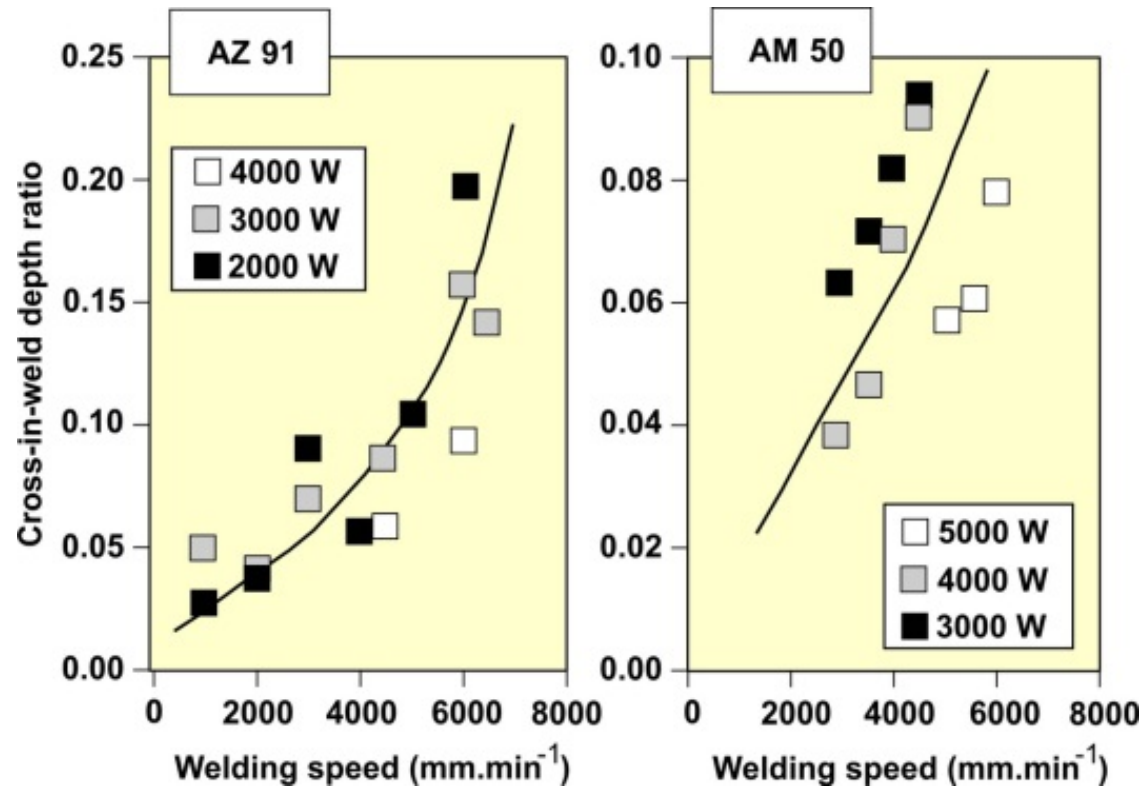

Figure 7. Effects of the beam speed and the beam power on the magnitude of the weld crown relative to the weld depth (Marya and Edwards, 2001). 


\subsection{Shielding gas}

It is well known that magnesium is highly susceptible to oxidation and thereby elaborate protection from the atmosphere is required (Dilthey et al., 1998). This can be achieved using inert gases. Good shielding can prevent burning or porosity and protect the laser optics from metal slag. The shielding gas also influences the formation of the plasma (Dhahri et al., 2001b). Helium, with a high ionization potential of $24.5 \mathrm{eV}$ and good thermal conductivity, has a high plasma formation threshold. Thus, little plasma is produced using helium as shielding gas (Cao et al., 2006).

To identify the best shielding gas, blind welds of AZ91 alloy were produced using helium, argon and nitrogen ( $\mathrm{Yu}$ et al., 2009). Helium gas is proved to be the best according to the surface roughness, penetration depth, and seam shape factor (depth/width). Studies on welding of WE43 alloy using a $5 \mathrm{~kW} \mathrm{CO}$ laser reveals that gas flow of He lower than 50 1/min may cause spraying or collapse of the molten pool (Dhahri et al., 2001a). A comparative study of two kinds of inert shielding gases He and Ar for laser welding process showed that He gas possesses a better shielding effect for the laser generated magnesium alloy pool than Ar gas, because of its higher dissociation energy and better conductivity (Dhahri et al., 2001b). For $\mathrm{CO}_{2}$ laser welding process, the satisfied seams with smooth surface, deep penetration depth, large ratio of weld depth to weld width and high weld strength, could only be produced under the protection environment of much more expensive He gas. In contrast, for the YAG laser welding process, sound seams could be readily obtained under the protective environment of much cheaper Ar gas. It can be concluded that YAG laser is the first choice for the laser welding of magnesium alloys considering weld quality and economic factors (Dhahri et al., 2001b). It was found that the shielding gas configuration could have a significant effect on the weld quality. Welding configurations are shown in Fig. $8 \mathrm{a}$ and $8 \mathrm{~b}$.
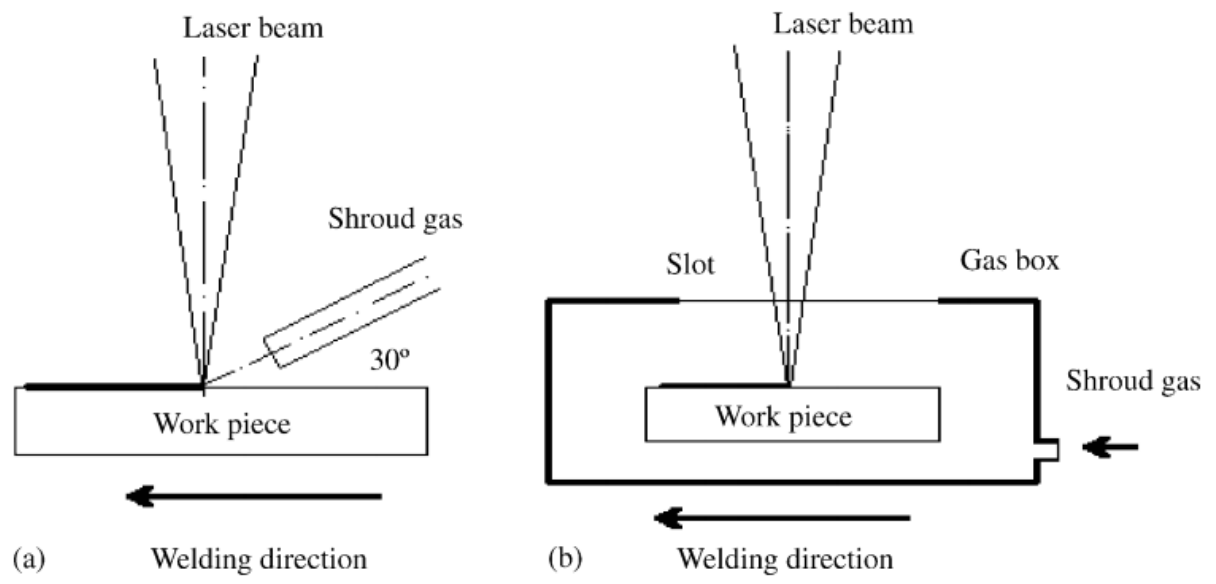

Figure 8. Welding configuration (a) with a shroud gas feed tube and (b) in a gas box (Zhu et al., 2005). 
If the gas flow was too weak, there would be insufficient weld protection, while too strong the gas flow would disturb the weld geometry, or cause defects. When the gas from the feed tube above the weld is not aligned with the traverse direction, a side cut would occur as shown in Fig. 9. Besides, if it is in the opposite direction with that, shown in Fig. 2, an irregular weld bead would occur. When the laser welding was conducted in the gas box, a reasonable weld can be made more easily.

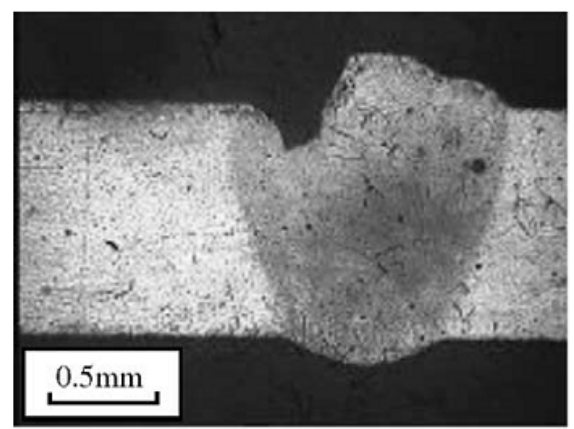

Figure 9. Slide blow defect in AZ31 laser welds (Zhu et al., 2005).

Therefore, gas shroud configuration is very important, which affects the weld zone oxidation and weld beam geometry. The use of an atmospherically controlled glove box is more effective.

\subsection{Fiber laser}

Fiber laser, as the third generation of industrial laser, is rapidly developing in recent years due to a number of advantages such as compact size, long transmission distance, high efficiency, superior beam quality and high power output (peak output is up to $50 \mathrm{~kW}$ ). In the fields of joining steel and aluminium alloys, fiber laser has made a big progress in experimental studies and industrial applications, showing a great potential to replace conventional $\mathrm{Nd}$ :YAG and $\mathrm{CO}_{2}$ lasers. However, few studies on welding magnesium alloys by fiber lasers are conducted. It is reported that the UTS of the joint decreases, but the yield strength increases after fiber laser welding of fine-grained magnesium alloy (Yu et al., 2009). An IPG YLR 6000W fiber laser and a KUKA KR60 robot are shown in Fig. 10.

Using of $6 \mathrm{~kW}$ fiber laser to weld AZ31B wrought magnesium alloy showed that the impact of welding speed on the weld penetration depth is less than that of laser power, though the weld penetration depth increases with decreasing the welding speed (Wang et al., 2011). The effects of welding parameters on weld penetration depth are depicted in Fig. 11. It can be found that the weld penetration depth only increases by $0.5 \mathrm{~mm}$ or so as the welding speed decreases from $4 \mathrm{~m} / \mathrm{min}$ to $2 \mathrm{~m} / \mathrm{min}$ when the laser power is kept the same. On the other hand, laser power plays a big role in the characterization of fiber laser welding of AZ31B magnesium alloy. The weld penetration depth increases by 2-3 $\mathrm{mm}$ per kilowatt in laser power. It is found that in the range of 2.5 to $4.0 \mathrm{~kW}$ laser power, stable welding process and accepted welds without macro-defects can be obtained (Wang et al., 2011). 


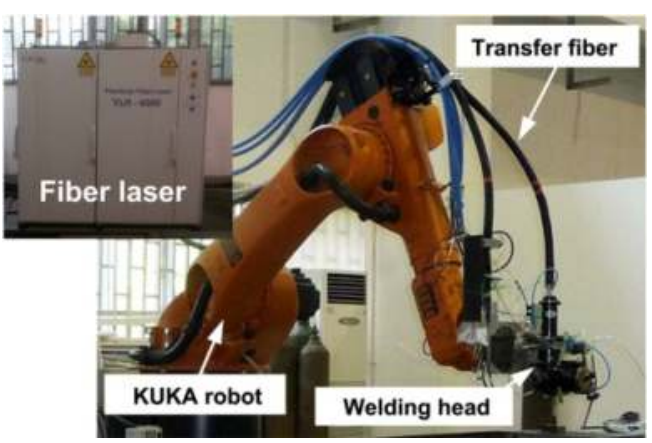

(a)

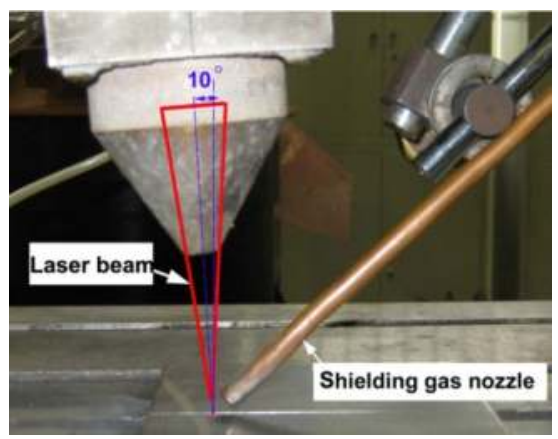

(b)

Figure 10. Diagrams of fiber laser welding system and experimental arrangement, (a) IPG fiber laser installed on a KUKA robot, (b) welding head (Wang et al., 2011).

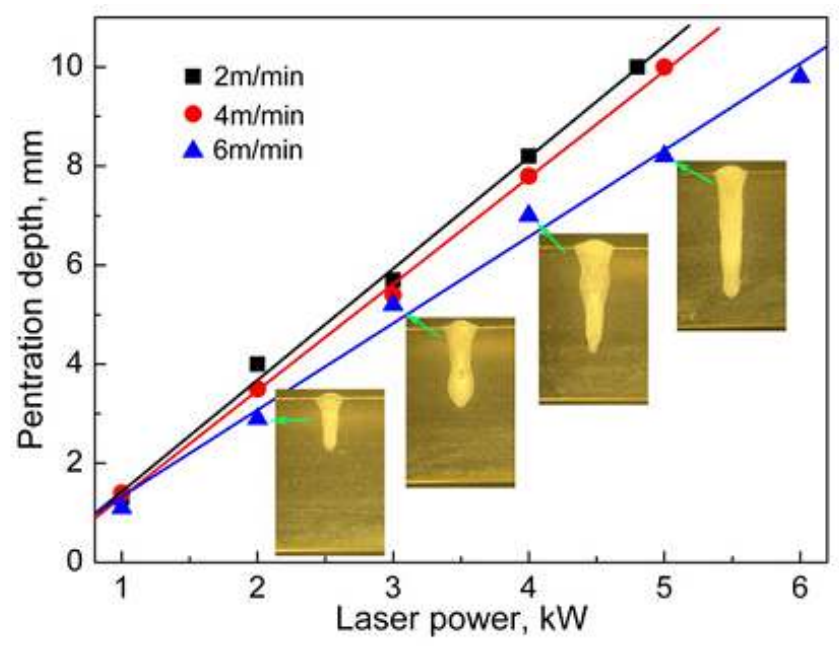

Figure 11. Effects of welding parameters on weld penetration depth (Wang et al., 2011).

\subsection{Microstructure}

In the laser welding, three distinct regions can be distinguished in the weld cross section, i.e., the fusion zone (FZ), partially melted zone (PMZ), and the heated affected zone (HAZ), which are categorized according to the temperatures experienced during welding. A narrow weld joint is an important characteristic of high power density welding. FZ, PMZ and HAZ for ZE41A-T5 alloy joint are shown in Fig. 12. 

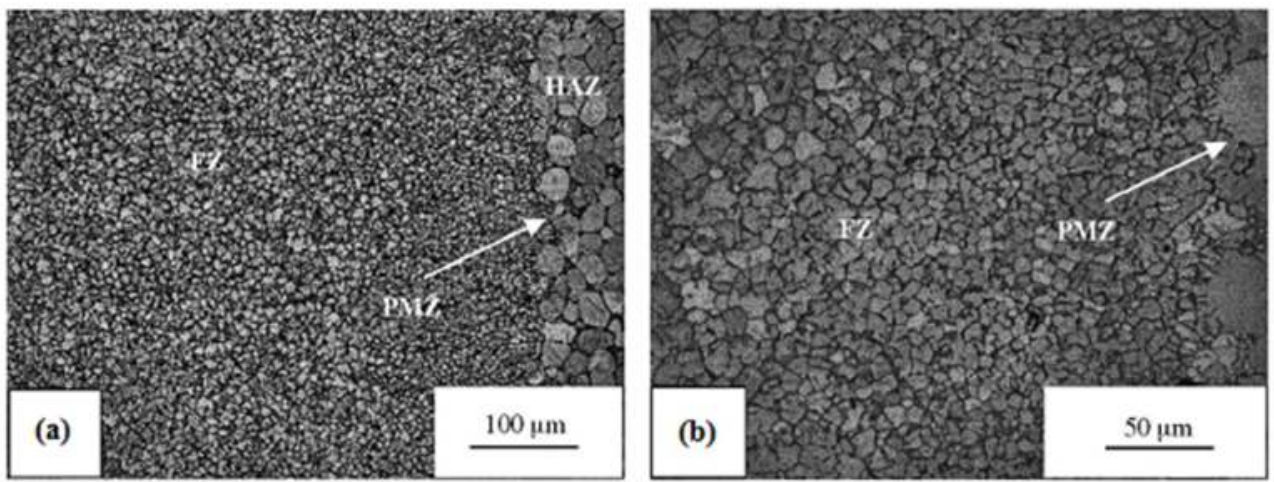

Figure 12. Optical micrographs showing (a) microstructure near the interface between the FZ and HAZ for a ZE41A-T5 alloy joint and (b) close-up view of Fig. 12a (Cao et al., 2005).

The $2.5 \mathrm{~kW} \mathrm{CW} \mathrm{Nd:YAG} \mathrm{laser} \mathrm{welding} \mathrm{of} 2 \mathrm{~mm}$ ZE41A-T5 sand castings showed that the fusion zones have widths of approximately $0.8-1.3 \mathrm{~mm}$ and the width of HAZ is approximately $2 \mathrm{~mm}$ and the partially melted zone is rather narrow, only several grains wide. It is showed that the HAZ in welded AZ91D die castings using a $2 \mathrm{~kW} \mathrm{CW} \mathrm{Nd:YAG} \mathrm{laser} \mathrm{had} \mathrm{a}$ width of 50-160 $\mu \mathrm{m}$ which is depending on welding speed (Haferkamp et al., 1996). Moreover, $2 \mathrm{kWPW}$ Nd:YAG and $6 \mathrm{~kW} \mathrm{CW} \mathrm{CO} 2$ laser welding of wrought AZ31B alloy indicated that the width of the HAZ was 50-60 $\mu \mathrm{m}$ (Haferkamp et al., 2000). If the base metal is work hardened, the strengthening effect will be removed. If the alloy is in a fully tempered state, the loss of precipitates may lead to the HAZ overaged. If the alloy is susceptible to grain growth, the grains will grow in the HAZ which leads to decrease in mechanical properties (Cao et al., 2006). A significant grain coarsening can be observed in the HAZ in wrought AZ31 alloy, however, in all laser welded cast alloys, no grain coarsening occurs within the HAZ zone. Certainly, grain growth can be minimized at high welding speeds (Cao et al., 2006).

\subsection{Metallurgical defects}

\subsubsection{Porosity}

The presence of porosity in the weld is one of the major concerns during laser beam welding of magnesium alloys. The high porosity is also one of the most important factors to reduce the failure strength of welded joints undergoing higher heat input, even though their grain size in the FZ is similar to or even smaller than that of the base metal (Wang et al., 2011). During the tensile test, because of stress concentration around the porosities, the microcrakes usually initiate from these weakest positions, and then propagate to fracture the joints (Zhao and Debroy, 2001).

Magnesium has significantly high solubility for hydrogen in the liquid phase and the porosity in magnesium alloys is dependent on the amount of dissolved hydrogen (Stolbov et al., 
1990). The tolerable hydrogen gas content in welds may depend on a number of factors such as the parameters of the welding process, alloy composition, local solidification time, thermal gradient, weld structure, and inclusion concentration (Cao et al., 2006). However, no acceptable hydrogen content limits have ever been reported for laser welded joints of magnesium alloys. With magnesium alloys containing zirconium, hydrogen will react with zirconium to form $\mathrm{ZrH} 2$, and finally in this case, hydrogen porosity will not be a problem (Cao et al., 2006), (Cao et al., 2005). It is found that the rejection of hydrogen from the Mg17Al12 intermetallic compound helped in the nucleation and/or growth of micro-porosity during the last stages of solidification of AZ91 alloy. It was recognized that the porosity in fiber laser welds of AM60, AE42 and AS41 cast magnesium alloys was mainly caused by the growth of the initial pre-existing pores. Imperfect collapse of the keyhole and turbulent flow in the weld pool could also been linked with porosity formation. In the fiber laser of AZ31B wrought magnesium it is proposed that, the initial preexisting micro-pores plays a major role in the pore formation when the heat input increases to $85.7 \mathrm{~J} / \mathrm{mm}$ or higher, while the collapse of the unstable keyhole is the main reason for the pore formation when the heat input is lower than $62.5 \mathrm{~J} / \mathrm{mm}$ (Wang et al., 2011). Thus, decreasing heat input is effective to reduce the porosity in fiber laser welds of magnesium alloys. Fig. 13 depicts the effect of welding speed on the pore fraction in AZ91 alloy.

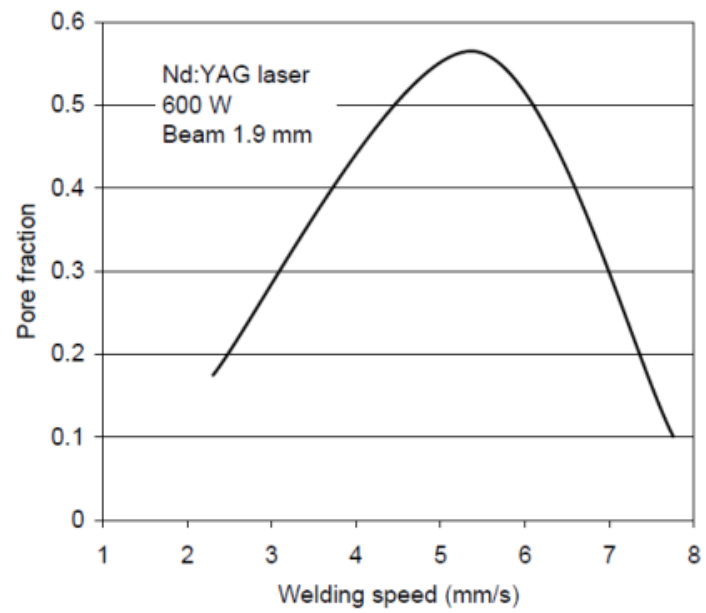

Figure 13. Effect of welding speed on the pore fraction in AZ91 alloy.

The existence of gas inclusions in the base metal is another important factor in contributing to the formation of large pores during Nd:YAG laser welding of magnesium alloys (Zhao and Debroy, 2001). As shown in Fig. 14a hydrogen porosity is the dominant pore in laser welded die-cast magnesium alloys because of their extremely high initial gas contents. Clearly, production of weldable and heat treatable die-castings necessitates the reduction of gas contents in magnesium alloys (Cao et al., 2006). Vacuum die-castings have relatively low initial gas contents. 


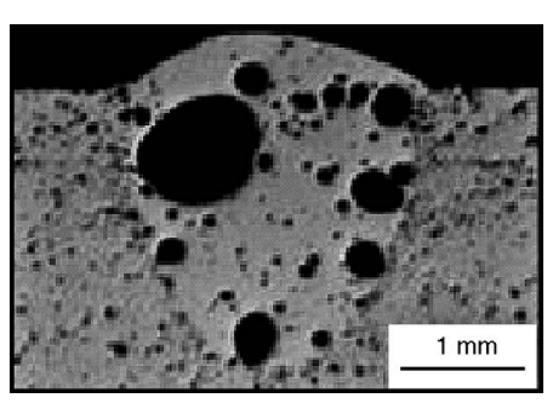

(a)
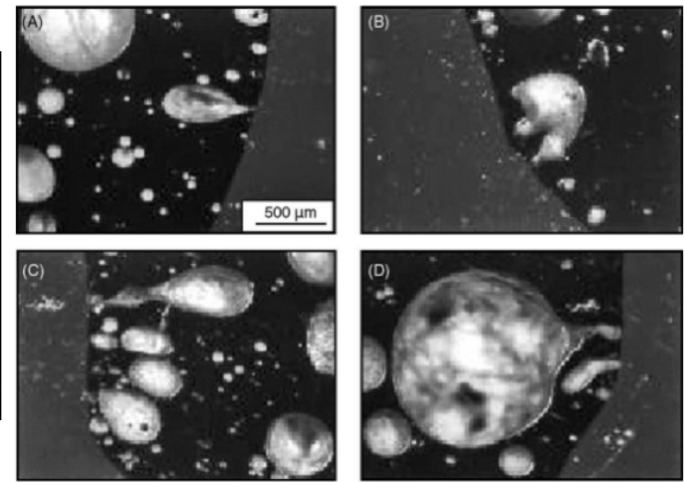

(b)

Figure 14. (a) Pores in die-cast AM60B alloy welded using a $1.5 \mathrm{~kW} \mathrm{CW} \mathrm{Nd:YAG} \mathrm{laser} \mathrm{(Zhao} \mathrm{and}$ Debroy, 2001), and (b) Formation of large pores in the FZ due to the expansion and coalescence of the preexisting pores in base die-cast AM60B alloy (Cao et al., 2006).

The porosity in the FZ increases with the increase in heat input, i.e., increase in the laser power and decrease in the welding speed. It is proposed that well-controlled remelting of the FZ leads to removal of gas bubbles and reduced porosity in the FZ. When die cast magnesium alloys remelt during laser beam welding, the gas can be enlarge due to heating (thermal expansion) and thus leading to the release of the gas pressure. Finally, the growth of porosity leads to expansion and coalescence of the pores, causing the formation of large pores in the fusion zone as shown in Fig. 14b (Cao et al., 2006).

\subsubsection{Weld cracking}

Hot cracks have been one of the main welding defects for magnesium alloys. In most magnesium alloys, an increase in alloying elements will generally increase the solidification temperature range. The large freezing temperature range, large solidification shrinkage, high coefficient of thermal expansion, and low melting point intermetallic constituents potentially make magnesium alloys susceptible to heat affected zone liquation cracking and solidification cracking in FZs (Marya and Edwards, 2002). In addition, a number of magnesium alloys are thought to be susceptible to stress corrosion cracking. Thus, the welded joints should be used after stress relieving (Cao et al., 2006).

\subsubsection{Solidification cracking}

Solidification cracking usually occurs in the alloys with large solidification interval, such as $\mathrm{Mg}-\mathrm{Zn}-\mathrm{Zr}, \mathrm{Mg}-\mathrm{Al}-\mathrm{Zn}$, etc. (Cao et al., 2006). The susceptibility to solidification cracking is evaluated using the circular-patch-weldability test and operating windows of welding parameters are identified (Lathabai et al., 2003). The alloys containing up to $6 \% \mathrm{Al}$ and up to $1 \% \mathrm{Zn}$ possess good weldability, while the alloys containing over $6 \% \mathrm{Al}$ and up to $1 \% \mathrm{Zn}$ are moderately crack sensitive, because of the occurrence of low melting-point constituents 
$\left(\mathrm{Mg}_{17} \mathrm{Al}_{12}\right)$. Even without $\mathrm{Al}$, the alloys containing over $3 \% \mathrm{Zn}$ are highly susceptible to solidification cracking and difficult to weld (Marya et al., 2000). On the other hand, hot tearing is mainly influenced by joint composition, microstructure, welding process parameters, and joint design. More investigation is needed to prevent the hot cracking.

\subsubsection{Oxide inclusions}

It is well known that, oxides are the main inclusions in magnesium alloys. It is found that, the presence of oxide inclusions in the base metal is thought to be an important factor in the formation of large pores during Nd:YAG laser welding of magnesium alloys (Haferkamp et al., 1996). Oxidation of magnesium is increased at high temperatures, resulting in the formation of a surface magnesium oxide layer (Cao et al., 2006). The amorphous structure of $\mathrm{MgO}$ films in solid pure magnesium generally performs an important role as a protective layer to prevent further oxidation at low temperature, but the films easily become porous and loose with the temperature increase. It is reported that the addition of $\mathrm{Ca}$ to the pure $\mathrm{Mg}$ as well as the addition of $\mathrm{Al}$ and $\mathrm{Y}$ to the $\mathrm{Mg}-\mathrm{Ca}$ alloys can further improve oxidation resistance. The entrapment of surface oxides into the molten pool during welding is an important source for oxide inclusions in laser welded magnesium alloys. Finally, it can be proposed that the surface oxides are formed during three stages: (i) oxygen chemisorptions, (ii) formation of the oxide layer (nucleation and lateral growth) and (iii) oxide thickening (Berlin et al., 2011). On the other hand the existing oxides in the base metal originating during primary metal processing or during casting is another source.

\subsubsection{Loss of alloying elements}

The relatively high vapour pressure of liquid magnesium compared with aluminium points to the potential problem of evaporative losses, particularly if zinc is also present as an alloying addition. The evaporation will cause a variation of chemical composition in the FZ, especially at high laser power density. Minimizing the irradiance incident upon the workpiece would decrease the loss of high vapour pressure elements (ASM, 1993). It is reported that low welding speed leads to larger reductions of both $\mathrm{Mg}$ and $\mathrm{Zn}$. it is expected that evaporative loss is more problematic in low zinc-zirconium alloys where zinc provides strengthening and zinc evaporation might decrease the properties to unacceptable levels. Further work is needed to fully understand the main influencing factors to build up the quantitative relationship between the element loss of evaporation and welding process parameters.

\section{Gas tungsten arc welding}

Gas-Tungsten Arc Welding (GTAW), also known as HeliArc, Tungsten Inert Gas (TIG), and tungsten arc welding, was developed in the late 1930s when a need to weld magnesium became apparent. Russell Meredith developed a welding process using the inert gas helium and a tungsten electrode to fuse magnesium. TIG welding is used extensively for welding stainless steel, aluminium, magnesium, copper, and reactive materials (for example, titanium and tantalum). This joining method replaced riveting as a method of building aircraft 
with aluminium and magnesium components (ASM, 1993). This process uses the heat, generated by an electric arc struck between a non-consumable tungsten electrode and the workpiece, to fuse metal in the joint area, and produce a molten weld pool. The arc area is shrouded in an inert or reducing gas shield to protect the weld pool and the non-consuming electrode. The process may be operated autogenously (without filler), or filler may be added by feeding a consumable wire or rod into the established weld pool. Fig. 15 illustrates the schematic of TIG welding process.

Advantages and limitations of GTAW include (ASM, 1993):

- $\quad$ Produces high quality, low distortion welds

- Free of the spatter associated with other methods

- Can be used with or without filler wire

- Can be used with a range of power supplies

- Welds almost all metals, including dissimilar ones

- $\quad$ Gives precise control of welding heat

- Produces lower deposition rates than consumable electrode arc welding processes

- Requires slightly more dexterity and welder coordination than gas metal arc welding or shielded metal arc welding for manual welding

- Less economical than consumable electrode arc welding for thick section greater than $9.5 \mathrm{~mm}(3 / 8 \mathrm{in})$

- Problematic in blowy environments because of difficulty in properly shielding the weld zone

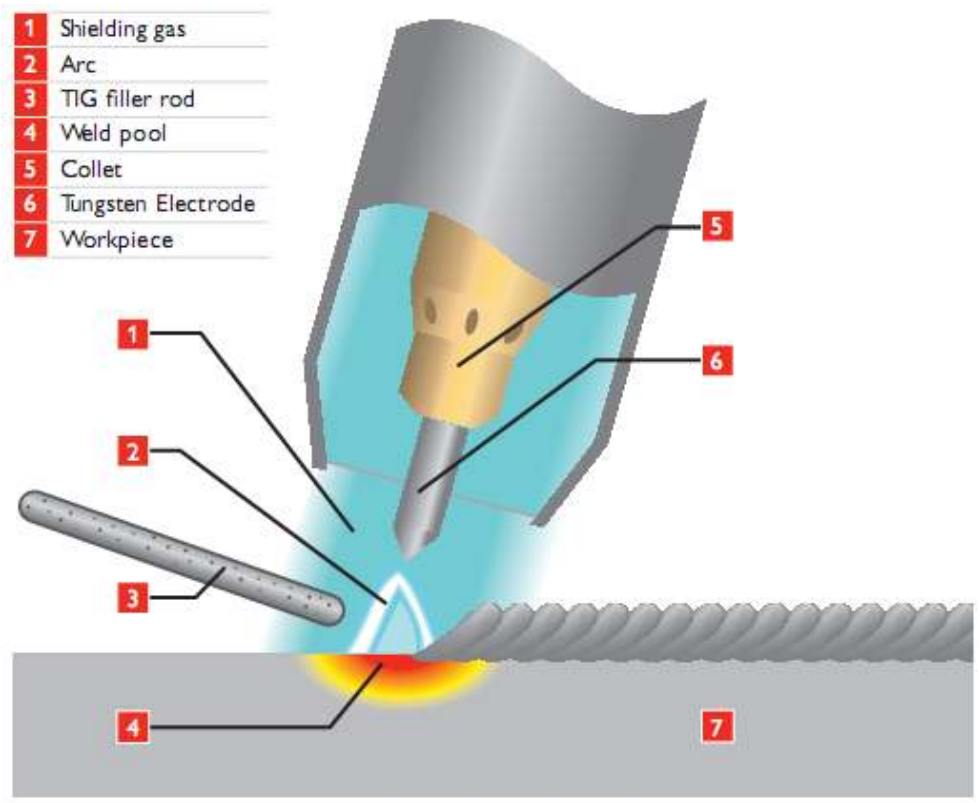

Figure 15. Schematic of TIG welding process (a) overall process; (b) welding area enlarged. 
Direct or alternating current power sources with constant current output characteristics are normally employed to supply the welding current. For direct current (DC) operation, the tungsten may be connected to either output terminal, but is most often connected to the negative pole. Shielding gas is directed into the arc area by the welding torch, and a gas lens within the torch distributes the shielding gas evenly over the weld area. In the torch, the welding current is transferred to the tungsten electrode from the copper conductor.

\subsection{Welding current}

Current is one of the most important process parameters to control in any welding operation, because it affects the penetration depth, welding speed, deposition rate, and weld quality. The TIG process may be operated in one of the following modes:

Direct Current Electrode Negative (DCEN): in this mode the tungsten electrode is the negative pole in the welding circuit, the workpiece being the positive pole (fig. 16a).

Direct Current Electrode Positive (DCEP): in this mode the tungsten electrode is the positive pole in the welding circuit, the workpiece being the negative pole (Fig. 16b).

Alternating Current (AC): in this mode the polarity of the tungsten electrode and the workpiece alternate between negative and positive at the frequency of the applied welding current.
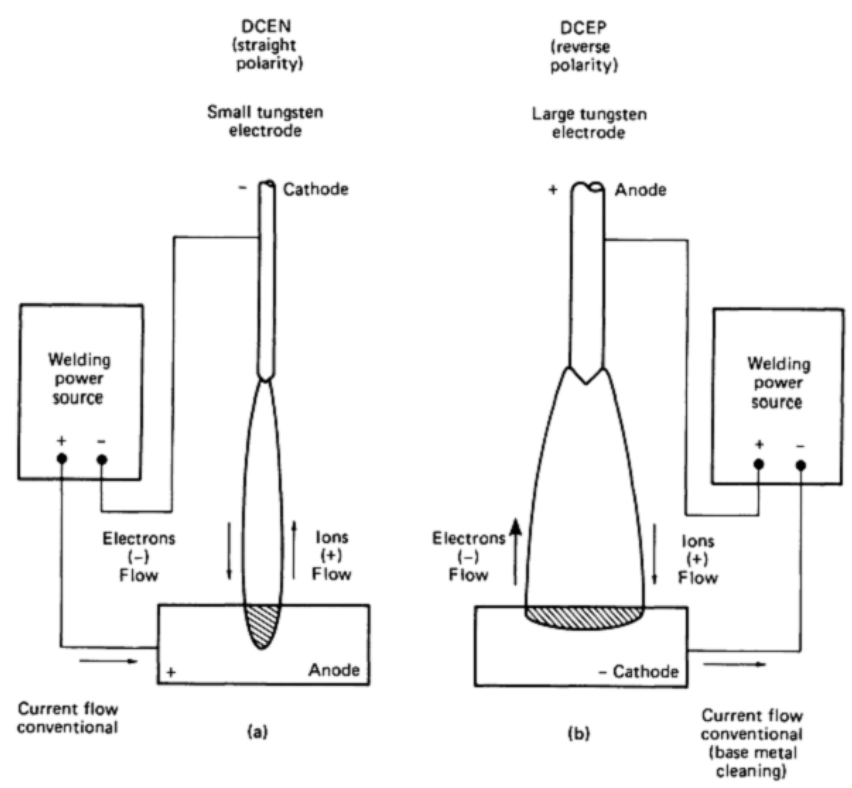

Figure 16. Effect of polarity on GTAW weld configuration when using direct current. (a) DCEN, deep penetration, narrow melted area, approximate $30 \%$ heat in electrode and $70 \%$ in base metal. (b) DCEP, shallow penetration, wide melted area, approximate $70 \%$ heat in electrode and $30 \%$ in base metal (ASM, 1993). 
In TIG welding of light metals, the alternate current is used, because the rapidly changing polarity gives combination of both cathodic cleaning action, which is beneficial for oxide removal during welding of aluminium and magnesium, and lower heat input. It is found that welding current affect the weld shape and arc voltage. The effect of welding current on weld penetration (D) and weld depth/width (D/W) ratio as well as arc voltage in AZ31B magnesium alloy with and without $\mathrm{CdCl}_{2}$ flux is shown in Fig. 17. It can be demonstrated that, with increasing welding current, the weld $\mathrm{D}$, the weld $\mathrm{D} / \mathrm{W}$ and arc voltage all increasing. The large welding current will increase the electro-magnetic force, which strengthens the downward body convection in the welding pool, leading to an increase in the $\mathrm{D} / \mathrm{W}$ ratio.
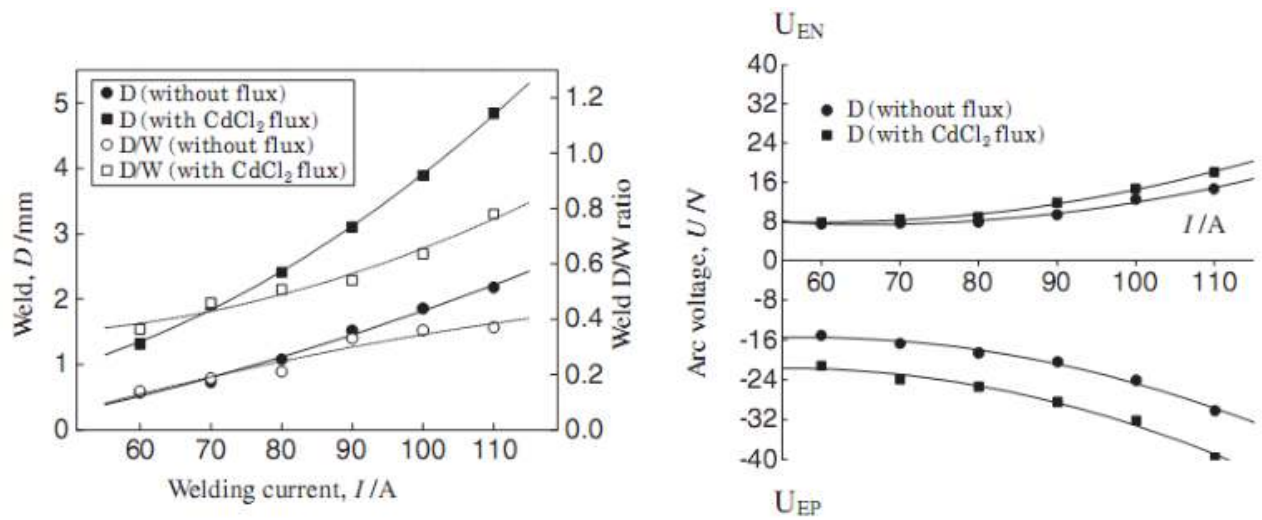

Figure 17. Effect of welding current on weld $\mathrm{D}$, weld $\mathrm{D} / \mathrm{W}$ ratio and arc voltage with and without $\mathrm{CdCl}_{2}$ flux (Marya and Edwards, 2002).

\subsection{Shielding gases}

The preferred gas for the AC-TIG welding of magnesium is argon, although helium and argon-helium mixtures may be used. Argon gives a wide, shallow penetration weld bead, but will leave the weld bright and silvery in appearance. Argon has a low ionization potential $\left(2.52 \times 10^{-18} \mathrm{~J}\right.$, or $\left.15.7 \mathrm{eV}\right)$, making it easier to form an arc plasma than with other shielding gases. The easiest arc ignition and most stable arc will also be achieved with argon. Argon, because of its high density, must be used at lower flow rates than helium. Typical flow rates for argon are $7 \mathrm{~L} / \mathrm{min}\left(15 \mathrm{ft}^{3} / \mathrm{h}\right)$, and for helium, $14 \mathrm{~L} / \mathrm{min}\left(30 \mathrm{ft}^{3} / \mathrm{h}\right)$.

For transition metal alloys, when the welding path is coated with chemical fluxes, a technique exists of flux-assisted gas tungsten arc welding (FA-TIG). Generally, fluxes allow full penetration welding at greater rates using relatively inexpensive gas tungsten arc as the heat source. Using argon shielding and chloride fluxes, magnesium alloy welding tests showed an increase in weld penetration (Marya and Edward, 2002). Among several chlorides, including $\mathrm{LiCl}, \mathrm{CaCl}_{2}, \mathrm{CdCl}_{2}, \mathrm{PbCl}_{2}$ and $\mathrm{CeCl}_{3}$, cadmium chloride is the most effective. The weld penetration of the GTA weld prepared with a $\mathrm{CdCl} 2$ flux is twice of that for the weld prepared without flux (Zhang et al., 2008). 


\section{Resistance spot welding}

Resistance spot welding is the localized joining of two or more metal parts together by the heat, generated using resistance to the flow of electric current through workpieces, which are held together under force by electrodes. The contacting surfaces in the region of current concentration are heated by a short-time pulse of low-voltage and high-amperage current. As a result, at the interface of welding sheets a molten pool (weld nugget) is formed. When the flow of current ceases, the electrode force is maintained till the weld metal cools down and solidifies. The electrodes are retracted after each weld, which usually is completed in a fraction of a second. RSW can be separated into Silicon Controlled Rectifier (SCR) AC resistance welding and inverter DC resistance welding (Hwang et al., 2010). For high electrical conductivity of magnesium and low heat generation in the weld, high welding currents are required. The process is used mainly in assembly lines to weld products made of thin gauge metals, and it has potentials for joining sheets of magnesium alloys (Xiaoa et al., 2011).

\subsection{Weld microstructure}

The joint, achieved by a technique of resistance spot welding, consists of the weld nugget and the heat affected zone. The weld nugget consists of the cellular dendritic structure at nugget edge, accompanied by equiaxed dendritic structure within its centre for AZ31 alloy (Fig. 18). The diameter of equiaxed dendrites in in the weld nugget of plates with lower thickness is smaller than that in the plates with higher thickness, and the length of columnar dendrites in the vicinity of the fusion boundary is also shorter.
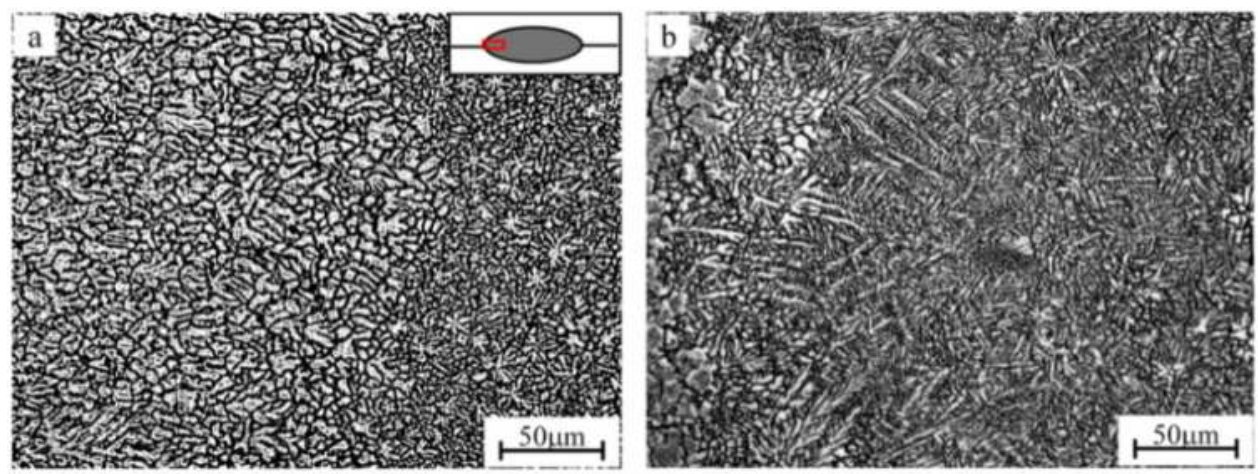

Figure 18. Equiaxed dendritic structure in the fusion zone of AZ31 Mg alloy resistance spot welds: (a) plate with a thickness of $2 \mathrm{~mm}$ and (b) plate with a thickness of $1.5 \mathrm{~mm}$ (Xiaoa et al., 2011).

The refined fusion-zone microstructure results in a longer fatigue life than welds with a coarse fusion-zone microstructure, when interfacial failure across fusion zone occurs at a 
higher level of cyclic load range (Xiaoa et al., 2011). The boundary melting and coarsening was observed in the heat affected zone. It is proposed that the weld nuggets have a tendency to hot cracking. The joint strength and cracking susceptibility are influenced by the welding current. While the higher current increases strength it also increases the nugget tendency to crack.

\subsection{Effect of welding parameters on joint properties}

As weld current increases, the nugget width increases as well. This effect is proved for both SCR AC resistance welding and inverter DC resistance welding which is shown in Table 1. In both RSW welding technics cracks and pores have been found, affecting the properties of weld. In the case of magnesium alloys, the welding part rapidly expands and retracts during welding and quickly cooling down, because of high coefficient of linear expansion. Then, a blank in the expanded space becomes pore (Yin et al., 2010). Thus, it is necessary to perform more investigations to reduce pore and crack.

\begin{tabular}{|c|c|c|c|c|}
\hline Current (kA) & 13 & 15 & 17 & 19 \\
\hline \multicolumn{5}{|l|}{ SCRAC } \\
\hline Nugget (mm) & 3.5 & 4.0 & 4.6 & 5.8 \\
\hline \multicolumn{5}{|l|}{ Inverter DC } \\
\hline Nugget (mm) & 3.9 & 4.4 & 5.0 & 6.0 \\
\hline
\end{tabular}

Table 1. Effect of welding current on nugget shape and size (Hwang et al., 2011).

It is confirmed that, the inverter DC resistance welding is more efficient than SCR AC resistance welding, in terms of heat input and weldability through shear tension strength, macro section and welding lobe (Hwang et al., 2011).

Fig. 19 shows the effect of selected process parameters on joint properties. With increasing the current, weld integrity reduces at the constant electrode force, as seen through porosity level (Fig. 19a). An increase in the electrode force reduces the role of current, and at sufficiently high electrode force the effect of current disappears. In the case without steel plates, the reduction in pore formation was achieved by increasing the electrode force and extending the holding time after current shut-off. The relative importance of holding time after current shut-off depended on welding current. 

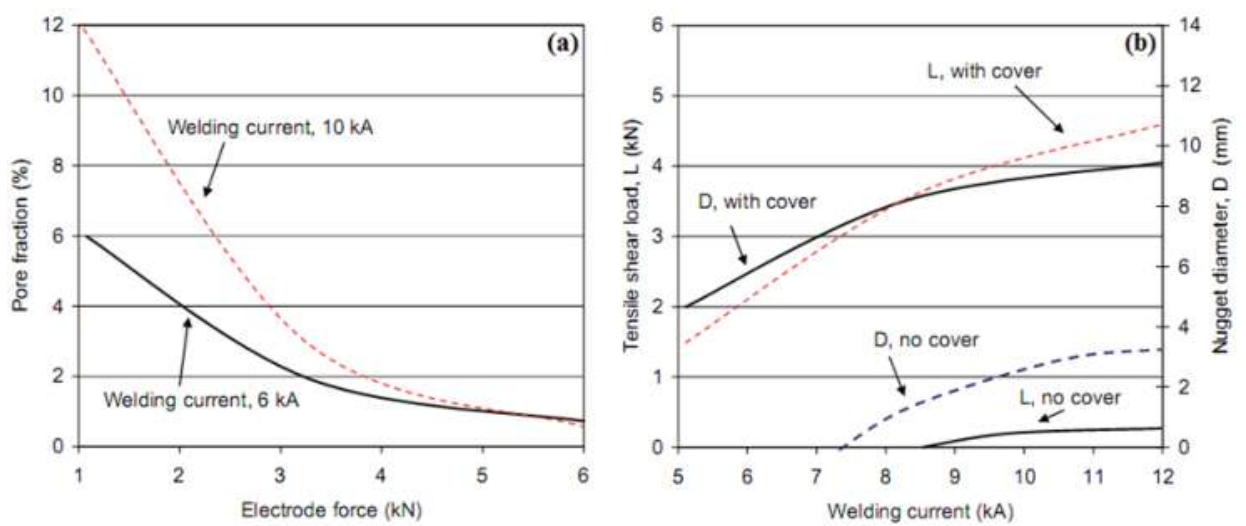

Figure 19. Resistance spot welding of AZ31B alloy with and without steel cover plates: (a) pore fraction versus electrode force; (b) tensile shear load and nugget diameter as a function of welding current (Shi et al., 2010).

\section{Electron beam welding}

Electron beam welding (EBW) is a process that melts and joins metals, employing a dense stream of high velocity electrons to bombard, heat, and melt the materials being joined. The electron beam is generated by electron gun, composed of a tungsten cathode and an anode placed in high-vacuum. Fig. 20 illustrates the schematic of EBW process. The beam currents and the accelerating voltages employed for typical EBW vary over the ranges of 50-1000 mA and $30-175 \mathrm{kV}$, respectively. A high intense electron beam can vaporize the metal and form a vapour hole during welding that is a keyhole (Fig. 20b). EBW process is suitable for difficult welding, where high repeatability is needed. Although laser welding is a very convenient method, its energy limitations restrict the degree of fusion penetration in thicker workpieces (Powers and Laflamme, 1992). Five factors control the EBW process and affect the quality of the weld, including accelerating voltage $(\mathrm{V}, \mathrm{kV})$, beam current $(\mathrm{I}, \mathrm{mA})$, welding speed $(v, \mathrm{~mm} / \mathrm{s})$, vacuum level (below $10^{-3}$ Torr), and the spot size $(\varphi, \mathrm{mm})$ of the electron beam on the surface of the workpiece (Chi et al., 2006).



Figure 20. Electron beam welding: (a) process; (b) keyhole (Kou, 2003). 
Advantages and limitations of RSW include (ASM, 1993):

- With a very high power density in EBW, full-penetration keyholing is possible even in thick workpieces.

- The total heat input per unit length of the weld is much lower than that in the arc welding, resulting in a very narrow HAZ and little distortion.

- Dissimilar metals can be welded because of the very rapid cooling which can prevent the formation of coarse, brittle intermetallic compounds.

- Equipment costs for EBW generally are higher than those for conventional welding processes. The requirement of high vacuum $\left(10^{-3}-10^{-6}\right.$ torr $)$ and $x$-ray shielding is inconvenient and time consuming.

- The available vacuum chamber capacities and workpiece size are limited. The fine beam size requires precise fit-up of the joint and alignment of the joint with the gun.

In the case of thermal effect during welding of AZ61 alloy, it is proposed that the welding heat source of electron beam produces two special thermal effects: (i) deep-penetration thermal effect and (ii) surface thermal effect of metal vapour (Luo et al., 2010). The experimental data for AZ61 alloy show that the key parameters affecting the keyhole thermal effect are the welding heat input and focus coil current, which has also an influence on the weld shape.

Increasing the $\mathrm{Al}$ content in EBW of $\mathrm{AZ}$ series of magnesium alloys (up to10\%) leads to increasing both the strength and micro-hardness of the weld, and decreases its ductility, because of the increase in concentration of brittle precipitates in the FZ (Chi et al., 2006).

During electron beam welding of $11 \mathrm{~mm}$ thick AZ31B plates with a power of $4000 \mathrm{~W}$ to 5000 $\mathrm{W}$ the effect of various process parameters is examined (Chi and Chao, 2007). The factors reducing the weld strength are: deviations of weld geometry, porosity and grain coarsening. In general, the weld strength reaches over $90 \%$ of that for the base alloy.

\section{Electromagnetic welding}

Electromagnetic welding is a phenomenon in which the current carrying conductors exert a force on each other. Fig. 21 shows a schematic diagram of magnetic pulse welding (MPW). This welding process can be classified as an impact welding technique, which is generally a set of processes that use a rapid energy source to accelerate and cause collision between two metal surfaces. The collision must take place at a high enough velocity to achieve bonding through contaminant and oxide removal. The sheet surfaces must make contact at a small angle, typically at least $4^{\circ}$, up to $\sim 30^{\circ}$. This creates a single dynamic collision point that travels along the surfaces as they collide and bend flat against one another. Some advantages of MPW process could be (Berlin, 2011): base-metal like bond strength, extremely high speed, dissimilar metal combination, no filler or shielding gas, and no HAZ.

Fig. 22 depicts $\beta$ (collision angle) and schematically represents the deformation taking place during double sided MPW, as carried out in AZ31 magnesium alloys. The joint morphology consisted of three distinct regions observed in cross section: an unbounded centre zone $\sim 3$ mm wide, twin bond zones $\sim 1 \mathrm{~mm}$ wide, and the outer unbounded surfaces which span the rest of the impact flattened area. The initial contact between the sheets was normal and the 
angle $\beta$ is negligibly small. Each bulge acts as a rigid barrier to the others forward motion. Two collision fronts progress symmetrically outwards from the initial contact area of the bulge peaks. Each of the twin bonds have the exact opposite welding direction of the other as well as $\beta$ at each front increases continuously (Berlin, 2011). The location between two bounded zones called unbounded centre zone.
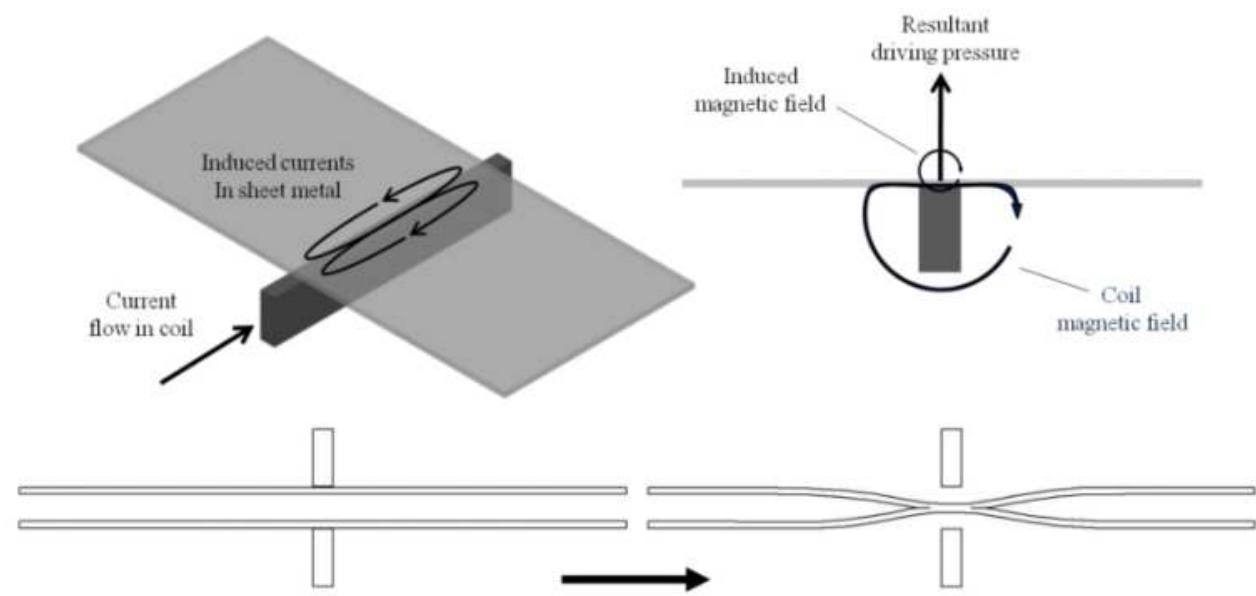

Figure 21. Schematic of the magnetic pulse welding process (Berlin, 2011).

Parallel

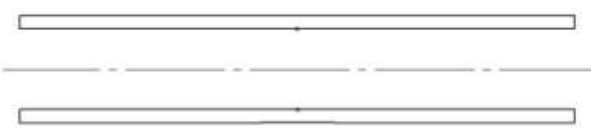

Flattening begins

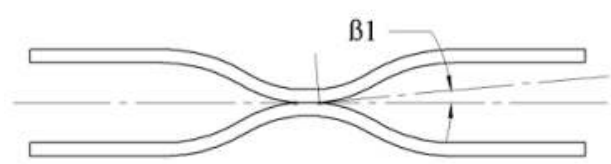

Bonding ends

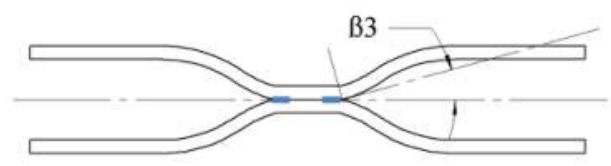

\section{Peaks Contact}

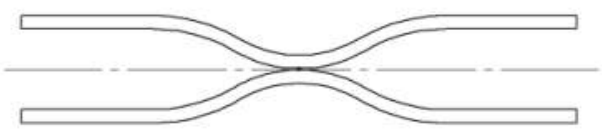

Bonding starts

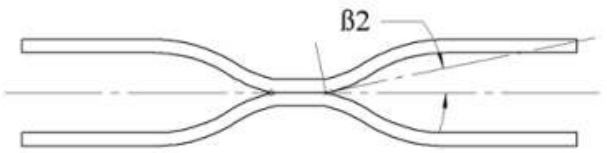

Comblete ioint

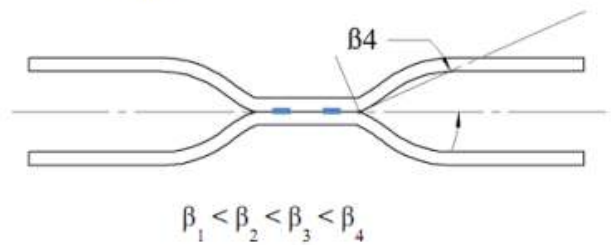

Figure 22. Schematic diagram showing the initial impact and flattening of the sheets during MPW (Berlin, 2011). 
Aizawa was the first to successfully weld two flat Al sheets in a lap joint configuration using MPW (Aizawa, 2003). Recently, most MPW researches are focused on joining dissimilar metals, with primary interest in the joint mechanical properties (Berlin et al., 2011). At present, there are some systematic investigations on the joining of magnesium to magnesium alloys using MPW or other forms of impact welding. During lap joints of magnesium AZ31 sheets using magnetic pulse welding, it is found that the bond displays high shear strength, almost equivalent to the base metal shear strength (Aizawa, 2003).

MPW is a technique provided satisfactory results for Al-AZ91 joint. The sheets with a thickness of 0.5 to $1 \mathrm{~mm}$ were seam welded, producing a weld having the width of $5 \mathrm{~mm}$. The weld thickness was $10 \%$ less than the original sheet thickness. The weld zone was created as a result of combined effect of heating by eddy currents and the strong impulse electromagnetic force (magnetic pressure) and no obvious fusion boundary was microscopically detected in the joint interface. The difference in electrical conductivities of $\mathrm{Al}$ and $\mathrm{Mg}$ led to the skin depth of $0.7 \mathrm{~mm}$ in $\mathrm{Al}$ and $0.6 \mathrm{~mm}$ in $\mathrm{Mg}$ alloys. Additionally, for the experimental conditions, the minimum discharge energy required for Electromagnetic welding process of AZ31 to AA 3003 sheet was found to be in range of 4.3-5.5 kJ (Kore et al., 2009). Further increase in energy results in severe plastic deformation and failure away from the weld in the plastically deformed zone.

The electromagnetic compression of tubular profiles with high electrical conductivity is an innovative joining process for lightweight materials. The components are joined using pulsed magnetic fields which apply radial pressures of up to $200 \mathrm{MPa}$ to the material, causing a symmetric reduction of the diameter with typical strain of about $4^{-10} \mathrm{~s}^{-1}$. Since there is no contact between components to be joined and the joining machine, there is not possible damage of the welded parts. The method was examined for aluminium alloys and has potentials for magnesium.

\section{Diffusion welding}

Diffusion welding (also known as diffusion bonding) is a metal joining process that requires the application of controlled pressures at elevated temperatures and usually a protective atmosphere to prevent oxidation (ASM, 1993). No melting and only limited macroscopic deformation or relative motion between the joining surfaces of the parts occurs during bonding. Since temperature does not exceed melting, it allows to eliminate many problems associated with fusion welding.

The mechanism of bond formation in diffusion welding is believed to be the deformation of the surface roughness in order to create metal-to-metal contact at asperities, followed by the removal of interfacial voids and cracks by diffusional and creep processes (ASM, 1993). There are three major stages of the bonding progress (Czerwinski, 2010) which are illustrated in Fig. 23. First, a contact between materials occurs through the mating surfaces. During the second stage, diffusion within grain boundaries predominates, thus eliminating pores and ensuring arrangements of grain boundaries. During the third stage, the volume diffusion dominates and process is completed. 


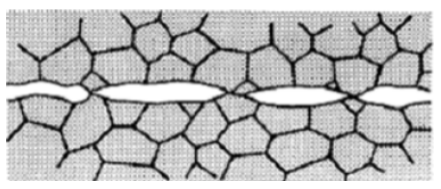

(a)

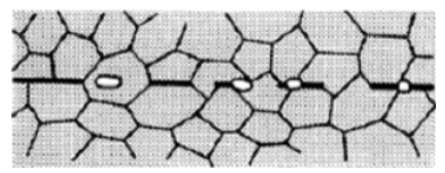

(c)

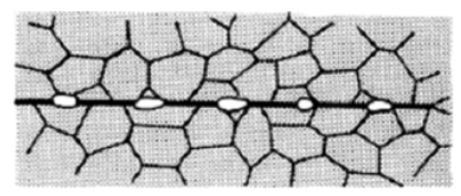

(b)



(d)

Figure 23. Three-stage mechanistic model of diffusion welding. (a) Initial asperity contact, (b) first stage deformation and interfacial boundary formation, (c) Second stage grain boundary migration and pore elimination, (d) Third stage volume diffusion and pore elimination (Czerwinski, 2010).

\subsection{Joints between magnesium alloys}

It is found that diffusion bonding is one of the applicable procedures for joining of pure magnesium and its alloys. The experiments were performed at the pressure range of 2-20 $\mathrm{MPa}$, temperature range from $300^{\circ} \mathrm{C}$ to $400^{\circ} \mathrm{C}$ and time periods up to $72 \mathrm{~h}$. Combination of diffusion bonding with superplastic forming is often employed for manufacture of complex sheet structures. This combination allows to reduce weight and fabrication cost in comparison with mechanically fastened structures (Gilmore et al., 1991). The technology is successfully implemented for commercial wrought AZ31 magnesium alloy. The results of different experiments are summarized in Table 2.

\begin{tabular}{cccc} 
Grain size $(\mu \mathrm{m})$ & Bonding time (hour) & $\begin{array}{c}\text { Bonding pressure } \\
(\mathrm{MPa})\end{array}$ & $\begin{array}{c}\text { Lap shear strength } \\
\text { ratio }\end{array}$ \\
\hline 11 & 3 & 5 & 0.90 \\
\hline 28 & 2 & 3 & 0.92 \\
\hline 17 & 3 & 3 & 0.85 \\
\hline 8.5 & 1 & 20 & 0.68 \\
\hline
\end{tabular}

Table 2. Combination of diffusion bonding with superplastic forming which is used for superplastic wrought AZ31.

In general, the superplastic high temperature deformation mechanism and diffusion bonding have grain size dependency, as structures with finer grains will have lower bonding temperature (Somekawa et al., 2003).

\section{Hybrid welding}

Hybrid laser beam technologies are defined as a combination of a laser beam source with an additional secondary beam source or another joining technique. The use of hybrid heat sources for welding is relatively recent and the topic is of great interest. A hybrid laser-TIG 
welding (LATIG) of AZ31 alloy, gives higher welding speed than in laser or TIG welding (Liu et al., 2004) which a schematic of LATIC is shown in Fig. 24. The results found that joint penetration could be increased; arc stability improved and cost decreased.

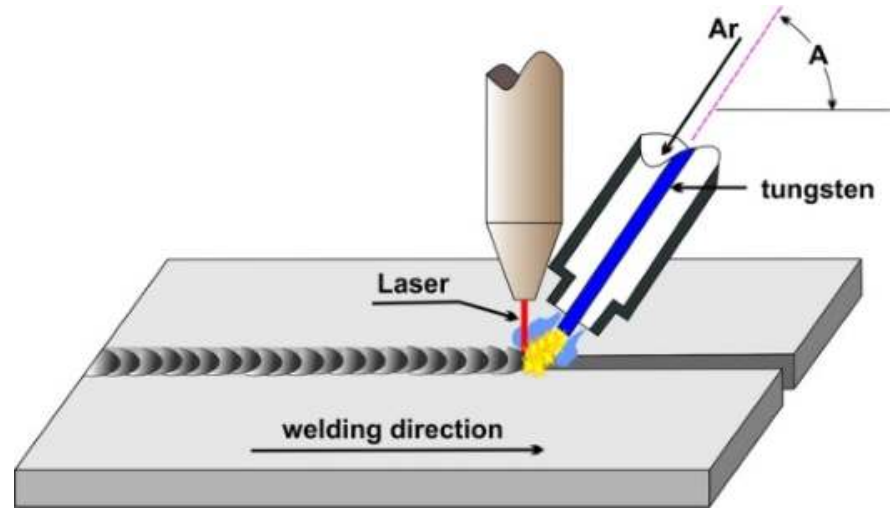

Figure 24. Principle of hybrid laser-TIG welding process.

The penetration depth is twice of that for TIG and four times of that for laser welding. A new method of hybrid joining, called laser continuous weld bonding, was developed as an alternative to laser welding and adhesive bonding (Liu and Xie, 2007). The technique was successful in joining of AZ31B magnesium and A6061 aluminium alloys by reducing a volume of brittle intermetallic compounds of $\mathrm{Al}_{3} \mathrm{Mg}_{2}$ and $\mathrm{Mg}_{17} \mathrm{Al}_{12}$ phases which are formed in the fusion zone, reducing the joint strength. The intermetallic phase formation was reduced due to the fluid generated by the gasification of adhesives. It appears that rising of adhesive vapour slows down the downward movement of liquid $\mathrm{Mg}$, thus reducing its content in the weld. Hence, the weld is composed of two-phase mixture with less intermetallic compound and more solid solution.

\section{Friction stir welding}

In fusion welds the chemical composition of melt catches more attention, and fillers or consumable electrodes maybe are used. Also, the process maybe requires a neutral atmosphere to avoid the oxidation of melt. Sometimes surface preparation before welding is also essential. Several defects and difficulties due to the melting and solidification come to pass, resulting in weakness of mechanical properties such as tensile strength, fatigue properties and formability. From the other difficulties of these jointing methods, it can be implied to the porosity, oxidation, hot and cold cracks, and also inability of joint dissimilar metals with different thermal expansion coefficients.

"Solid state welds" are the processes in which the joint is formed below the melting temperature of material. Therefore, the oxidation does not occur and there is no need for shield gas, neutral atmosphere, and consuming material. Solid state welds consist of the processes such as friction, ultrasonic, forging, and explosion welding. Three major factors of Time, Temperature, and Pressure, solely or in combination can generate the weld joint. 
Friction welding creates a joint without using filler metal, by converting the mechanical energy to the heat and the plastic deformation. Friction welding is divided into three categories: (i) rotational friction welding, (ii) non-rotational friction welding, and (iii) friction stir welding.

The rotational friction welding was the first friction welding which found commercially use. In this process, one of the cylindrical workpieces rotates concentrically to the other one, while two faces of cylinders are in contact. The material in the interface becomes soften, and then two cylinders are forged into each other (Fig. 25). This welding method is used for similar and dissimilar materials.
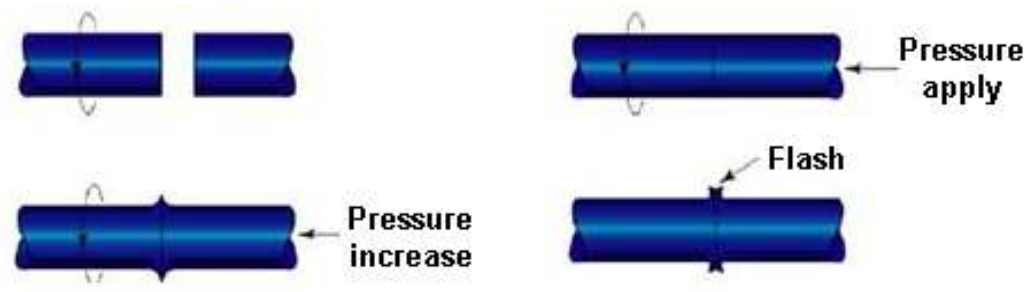

Figure 25. Schematic illustration of rotational friction welding.

In non-rotational friction welding the linear, orbital or angular movements are used to join the rectangular straps.

Friction stir welding (FSW), as a solid-state joining process, is invented by Wayne Thomas and his colleagues at The Welding Institute of UK in 1991. Although it was primarily applied on aluminium, it is now widely used for joining dissimilar metals together such as different aluminium and also magnesium, copper and ferrous alloys. FSW is believed to be the most important development in joining of metals in the past two decades.

The difficulty of making high-strength, fatigue and fracture resistant welds in aerospace alloys especially aluminium alloys, such as highly alloyed 2XXX and 7XXX series, has restricted the wide use of welding for joining aerospace structures. These aluminium alloys are generally classified as non-weldable, because of the poor solidification microstructure and porosity in the fusion zone. Also, the weakness of mechanical properties compared to the base metal is very noticeable. These factors have made the welding of these alloys unpleasant by the conventional methods.

Thus, in friction stir welding, which is a developed form of friction welding, the major aim is to join the materials which are hard to joint by the fusion welding processes. In the conventional friction welding, the heat is generated by friction between to faces in the joining interface. However, in FSW a third substance as a non-consumable, wear-resistant, rotating tool is inserted into the mated edges of jointing sheets and traversed along the joint line (Fig. 26a). The tool includes two main parts: (i) shoulder, to produce the frictional heat and support the softened material; and (ii) pin, to stir the material. Fig. 26b and 26c show a simple and a specially designed FSW tool. The pin and the shoulder possess special designs, which govern the process parameters and also resultant weld properties. Exactly, the tool 
provides two primary functions: (i) heating of workpiece, which is induced by friction between the tool and the workpiece, and also plastic deformation of the material; and (ii) movement of material to create the weld. The material around the pin is softened by concentrated heat, and moved from the front to the back of the pin by combination of tool rotation and translation. Finally, the moved material to the back of the pin is forged to weld nugget by the tool shoulder, resulting in a fine joint. Due to the various geometrical features of the tool, the material flow around the pin is quite complex. During FSW, the material undergoes an intense plastic deformation at the high temperature, resulting in a recrystallized microstructure with the fine equiaxed grains, and consequently good mechanical properties (Mishra and Ma, 2005).

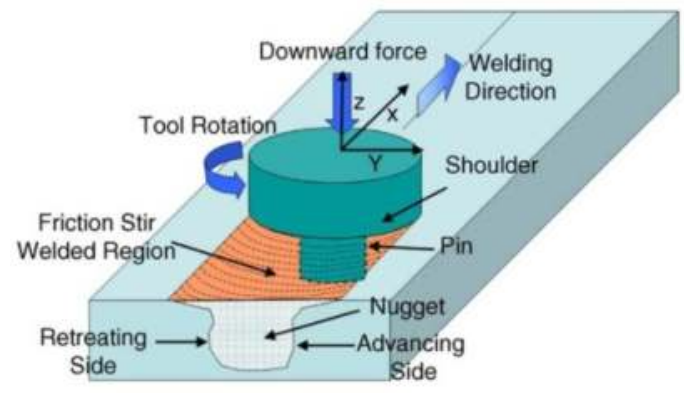

(a)

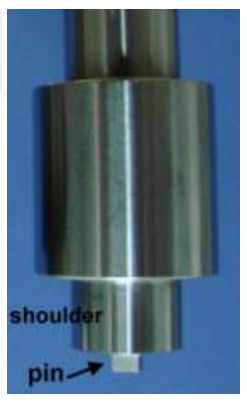

(b)

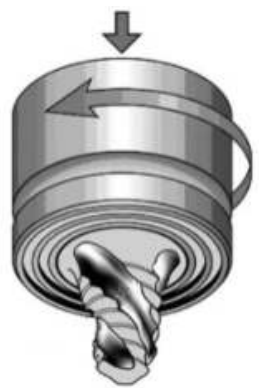

(c)

Figure 26. (a) Schematic illustration of FSW, (b) a simple FSW tool, and (c) an especially designed FSW tool.

Because of energy efficiency, environmental friendliness, and versatility, FSW is called as a green technology. In comparison with the conventional welding processes, FSW consumes significantly less energy, i.e., only $2.5 \%$ of the energy required for laser welding. No shielding gas or flux is needed and the poisonous gases are not generated, thus the process is nature friendly. The tensile strength and fatigue properties of products are appropriate and no filler metal is needed to use. Dissimilar aluminium and magnesium alloys, and composites can be joined with equal ease, and the thermal conduction coefficient is less important in compare with the fusion welding processes (Mishra and Ma, 2005). Contrary to the conventional friction welding, which is usually applied on small axisymmetric parts, FSW can be implemented for various types of joints like butt, lap, T butt, and fillet joints. As a result of the low heat experienced by the material, the products have excellent dimensional stability and repeatability, and also there is no loss of the alloying elements.

Since there is no melting of the material in FSW, fewer defects than the fusion welding processes are seen. In this process the HAZ, presenting many defects and the main reason for deterioration of mechanical properties, is very narrow. Due to the fact that the FSW does not involve any melting pool, the FSW is not limited to an especial position, and jointing sheets can be welded in any position. The process is simple and, in contrast to the fusion welds, 
does not need a proficient operator. This welding method is not sensitive to surface quality, and thus there is no need to degrease or remove the oxide layers.

\subsection{Process parameters}

FSW includes complex material flow which is induced severely by welding parameters and tool geometry. These parameters significantly affect temperature distribution, and therefore the microstructural characteristics of material.

\subsubsection{Tool geometry}

Tool geometry is the most consequential factor on the weld quality and has a crucial role in material flow. As declared before, the tool performs two primary functions of localized heating, and material flow. The tool is plunged till the shoulder touches the workpiece. The friction between the tool (shoulder and pin) and workpiece produces the biggest portion of heating. It is clear that, the amount of produced heat will increase as the shoulder diameter increases. The shoulder also supports the softened material during the process. The second task of the tool is to 'stir' and 'move' the softened material. This role commences when the tool travel starts along the welding line. In this case material undergoes a severe plastic deformation which results in an additional heating. The uniformity of microstructural and mechanical properties as well as process loads is governed by the tool design. Generally a concave shoulder and threaded cylindrical or square pins are used.

\subsubsection{Welding parameters}

Two process parameters in FSW are very important: tool rotational speed, and tool traverse speed along the welding line. The tool rotation results in stirring and mixing of softened materials around the pin, and the tool translation moves them from the front to the back of the pin and finishes the weld. Higher tool rotational speed to traverse speed ratio $(\omega / \mathrm{v})$ induces higher temperature due to the higher frictional heat, and results in stronger stirring of material. On the other hand, grain size in the SZ becomes larger with increasing $\omega / \mathrm{v}$, due to the increase in heat input, promoting the growth of recrystallized grains.

Besides the tool rotational and traverse speeds, another important process parameter is the "tilt angle" or "tool tilt" with regard to the workpiece surface. An appropriate tilt angle towards traverse direction ensures that the tool shoulder supports the stirred materials and moves them properly from the front to the back of the pin, and forges them into the weld nugget. Tilt angle can be adjusted between 0 and $6^{\circ}$.

Further, the tool penetration depth into the workpiece is another important factor to produce sound welds. When the penetration depth is too shallow, the contact surface between the tool shoulder and the workpiece is insufficient. Thus, the material will not be softened 
adequately, and then the tool will not be able to move the material efficiently, resulting in creation of tunnelling cavity or surface groove. On the other hand, if the penetration depth is too deep, the tool shoulder plunges into the workpiece, generating immoderate flash. With respect to the tool tilt angle, a sound weld can be achieved when one third to two third of the tool shoulder touches the workpiece surface.

\subsection{Microstructural characteristics}

In the cross section of friction stir welded parts, three distinct zones based on microstructural characteristics of grains and precipitates can be identified. As shown in Fig. 27 these zones are consisting of: stirred zone (SZ) (is called also nugget zone), thermomechanically affected zone (TMAZ), and heat affected zone (HAZ). Severe plastic deformation accompanied by high temperature during FSW results in recrystallization, grain refinement, and precipitate dissolution within the SZ (Mishra and Ma, 2005).

FSW causes the temperature to increase up to 0.6-0.9 of melting temperature (MT) of workpiece within the SZ. At such a high temperature, precipitates in alloys can coarsen or dissolve into the matrix depending on alloy type and peak temperature. Generally it can be mentioned that, a combination of dissolution, coarsening and/or reprecipitation of strengthening precipitates during FSW is possible to occur.

Unique to the FSW process, the TMAZ, which is created between the parent material and the SZ, experiences both high temperature and plastic deformation during the process. A typical TMAZ, characterized by a highly deformed structure, is shown in Fig. 28. This figure is related to the AZ91 magnesium alloy. As seen in the figure, $\alpha$ and $\beta$ phases have found an special orientation, and are prolonged within the boundary of the SZ and the BM. Recrystallization does not occur entirely in the TMAZ due to insufficient deformation strain and lower temperature, however dissolution of some precipitates or maybe partial recrystallization can be observed in the TMAZ.

As shown in Fig. 28, the basic microstructure of AZ91 magnesium alloy consists of primary $\alpha$-phase in which aluminium rich $\beta$-phase $\left(\mathrm{Mg}_{17} \mathrm{Al}_{12}\right)$ is precipitated along the grain boundaries. While the average grain size is about $150 \mu \mathrm{m}$ in the base metal, it is about $10 \mu \mathrm{m}$ in the SZ.

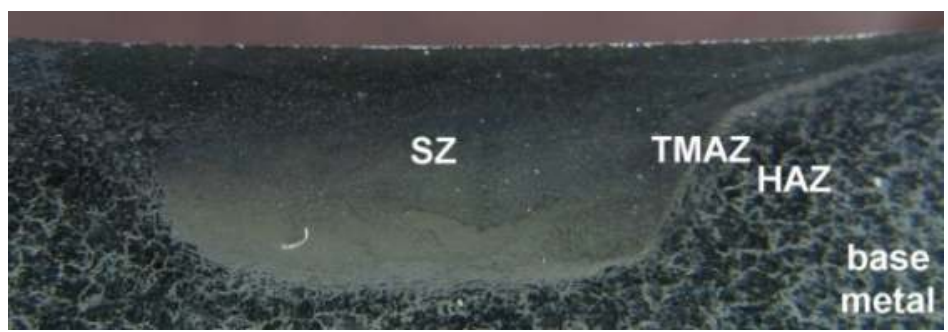

Figure 27. Various microstructural zones in the cross section of friction stir welded AZ91 alloy. 


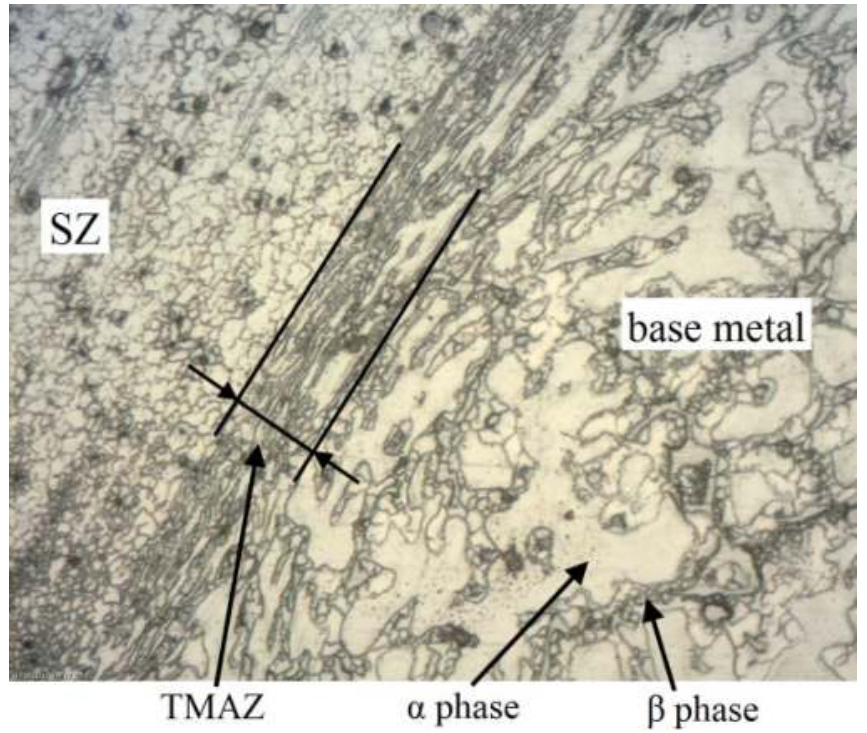

Figure 28. SZ, TMAZ, and base metal in friction stir welded AZ91 magnesium alloy.

Heat-affected zone, beyond the TMAZ, experiences a thermal cycle, but not any plastic deformation. The grain structure of the HAZ is as same as the parent material; however the thermal exposure above $0.4 \mathrm{TM}$ can exert an effect on the precipitate structure depending on alloy type.

\subsection{FSW of Magnesium Alloys}

Magnesium alloys, consisting hexagonal-closed pack structure, have poor formability, and sheet material of them is made by casting processes, except some wrought alloys such as AZ31. Therefore, it is almost difficult to weld these cast alloys by conventional methods due to the porosity formation. Furthermore, relatively high expansion coefficient of magnesium causes large deformation/distortion of product. Hence, FSW as a solid-state welding technique can be the optimum choice for welding cast magnesium alloy sheets. FSW studies, performed on different magnesium alloys, come together following considerable observations.

The quality of FSW of magnesium alloys is significantly sensitive to the tool rotational and traverse speeds which determine the amount of produced heat. It is reported that optimum parameter for FSW of AZ91 sheets are limited to a narrow range, i.e., higher tool rotational speeds and lower traverse speeds. Butt welding using square-pin tool can successfully perform at the optimum parameter combinations of traverse speed of $50 \mathrm{~mm} / \mathrm{min}$ and tool rotational speed of $900-1800 \mathrm{rpm}$. By decreasing the rotational speed, the traverse speed should be decreased relatively. Furthermore, increasing the shoulder to pin diameter rate can expand the optimum parameters range. Higher traverse speeds or lower rotational 
speeds than the optimum parameters caused the formation of tunnelling cavity or a lack of material bonding in the SZ. This is because of the poor formability of cast AZ91 magnesium alloy with a lot of intermetallic compounds, $\beta-\mathrm{Mg}_{17} \mathrm{Al}_{12}$, at the grain boundaries. Additionally, in order to evade sticking of magnesium to the tool during FSW, a relatively high rotational speed is utilized (Suhuddin et al., 2009). Similarly, for hot-rolled AZ31B-H24 reported that sound joints were produced only at higher $\omega / \mathrm{v}$ rates.

FSW of magnesium alloy usually does not generate a liquid phase (Mishra et al., 2005). Based on microstructural characteristics, the peak temperature is predicted to be between 370 and $500{ }^{\circ} \mathrm{C}$ within the SZ. On the other hand, simulation results show that the peak temperature in the $\mathrm{SZ}$ is about 380 to $550{ }^{\circ} \mathrm{C}$ depending on process parameters and tool design (Asadi et al. 2011a). However, a relative low tool traverse and high rotational speed can cause generation of liquid phase and a complex microstructure, especially in a thin layer at the top of the weld zone.

According to the $\mathrm{Mg}-\mathrm{Al}$ binary phase diagram, $\beta-\mathrm{Mg}_{17} \mathrm{Al}_{12}$ intermetallic compounds in AZ91 will dissolve into the magnesium matrix completely when the heating temperature is higher than $370{ }^{\circ} \mathrm{C}$. This critical temperature is $320{ }^{\circ} \mathrm{C}$ for the AZ61 and AM60 alloys. For ascast $\mathrm{Mg}$-Al alloys, the coarse continuous $\beta-\mathrm{Mg}_{17} \mathrm{Al}_{12}$ intermetallic phases disappear after FSW (see Fig. 28) and their particles exist both inside the grains and at the grain boundaries. These particles are spherical- or ellipsoidal-shaped, with the size range of 20 to $100 \mathrm{~nm}$ (Zhang et al., 2005). Although the peak temperature of $\mathrm{SZ}$ is high enough for $\mathrm{Mg}_{17} \mathrm{Al}_{12}$ to be dissolved into the magnesium matrix, but the temperature is not the entire problem (Zhang et al., 2005). Studies about the influence of heat treatment on microstructure revealed that, although partial dissolution of intermetallic compounds occur, most of the network structure (about $70 \%$ ) was remained untouched, after being heated at $350{ }^{\circ} \mathrm{C}$ for 1 hour (Mishra et al., 2005). Indeed, dissolution and re-precipitation could not be the main reason for the morphology change of intermetallic compound, since the thermal history of FSW is not adequate for this mechanism. On the other hand, the size and shape of intermetallic compounds changed mainly through mechanical fracture. The broken particles are distributed in the matrix of SZ with the material flow caused by tool rotation. Partial dissolution and coarsening will help the broken particles to further spheroidize in some degree (Zhang et al., 2005).

The hardness of the stirred zone depending on, process parameters, grain size, intermetallic components, and the way that the base metal is produced, can be higher or lower than the base metal. Variation of hardness with grain size is proved to follow the Hall-Petch relationship, as hardness increases with decreasing grain size. However, a reduction in hardness is revealed in the $\mathrm{SZ}$, due to coarsening of grains and/or dissolution of strengthening precipitates such as $\mathrm{Mg}_{17} \mathrm{Al}_{12}$.

FSW improves tensile properties of cast magnesium alloys such as AZ91 (Asadi et al., 2011b and 2012), while a reduction in tensile properties is observed in wrought magnesium alloys such as AZ31B-H24 and AZ61 (Mishra et al., 2005). For the FSW of AZ91D it is reported that in the case of transverse tensile test (perpendicular to weld line), all of the test specimens 
fractured in the base metal (Mishra et al., 2005), indicating the joint efficiency of $100 \%$ for these FSW joints. Longitudinal tensile tests revealed that the strength and elongation of the SZ were considerably enhanced compared to those of the base metal. In contrary, a reduction in tensile properties of FSW of AZ31B-H24 with a fracture close to the SZ in the transition region (TMAZ) is reported. Generally, it can be concluded that the joint efficiency of FSW for magnesium is very high $(80-100 \%)$. This means that, FSW is potentially excellent process for the joining of magnesium alloys (Suhuddin et al., 2009).

Additionally, by inserting some ceramic powders in the interface of jointing sheets, it is possible to produce a metal-matrix-composite weld. In this case, strength of weld nugget increases, but its elongation decreases compared to the case without ceramic powder.

One of the most important advantageous of FSW is possibility of making dissimilar joints. Typically, in dissimilar friction stir welding between 5052 aluminium alloy and AZ31 magnesium alloy, it is reported that the peak hardness in the SZ is twice higher than that of the base metals. The Vickers microhardness test was carried out along the dashed lines marked in Fig. 29a, which were $1.5 \mathrm{~mm}$ (top), $3 \mathrm{~mm}$ (middle) and $4.5 \mathrm{~mm}$ (bottom) to the upper surface, and the results are presented in Fig. 29b. The sharp fluctuations in hardness of the SZ are attributed to the onion ring structure and the intercalated microstructure. The tensile fracture position locates at the advancing side (aluminium side), where the hardness distribution of weld shows a sharp decrease from the stir zone to 5052 base material (Yong et al., 2010).

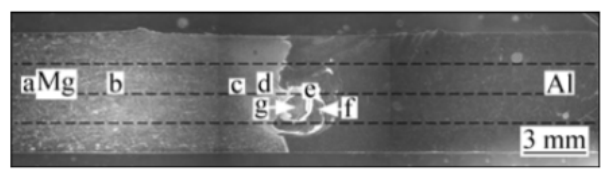

(a)

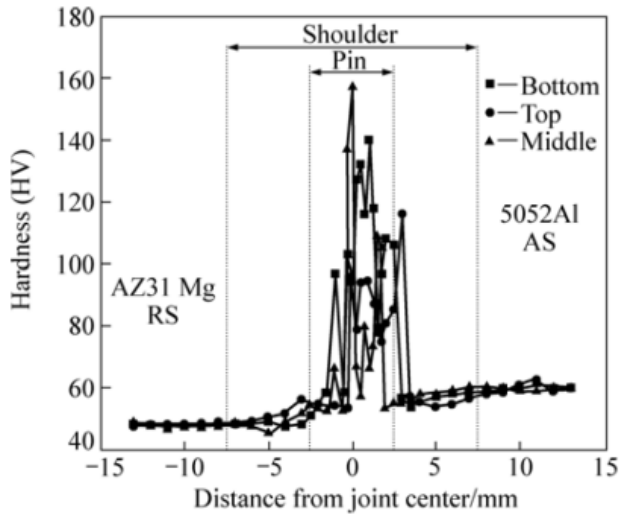

(b)

Figure 29. (a) Optical macrograph, and (b) Microhardness profiles of cross-section of dissimilar weld (Yong et al., 2010).

\section{Summary}

During last decade, a substantial proceed is made in welding and joining of magnesium alloys. To improve in conventional fusion welding techniques, new methods and their hybrids are developed. On the other hand, using non-fusion welding methods can also asset 
decreasing some metallurgical defects. Among the different welding processes for magnesium and its alloys, laser welding and friction stir welding will probably become efficient joining techniques. Crack-free laser welded joints with low porosity and good surface quality can be obtained for some magnesium alloys, in particular wrought material. Friction stir welding has overcome to most of the problems arose in the fusion welds. However, its drawbacks such as limited weld designs, high mechanical forces to jointing sheets, and thus requiring stronger fixturing may have confined its use. Indeed, joining techniques, which require local deformation, are not fully successful methods due to limited formability of magnesium, especially casting alloys such as AZ91. In this case, scientific investigations are still needed to understand and overcome these basic weldability problems of magnesium alloys.

\section{Author details}

\section{Parviz Asadi}

School of Mechanical Engineering, College of Engineering, University of Tehran, Tehran, Iran

Kamel Kazemi-Choobi

Research Center for Advanced Materials and Mineral Processing, Faculty of Materials Engineering, Sahand University of Technology, Tabriz, Iran

Amin Elhami

Department of Mechanical Engineering, Tehran Central Branch, Islamic Azad University, Tehran, Iran

\section{References}

Aizawa T. (2003). Magnetic pressure seam welding method for aluminium sheets, Welding Int., Vol. 17, pp. (929-933).

Asadi P., Mahdavinejad R.A. and Tutunchilar S. (2011). Simulation and experimental investigation of FSP of AZ91 magnesium alloy, Materials Science and Engineering A, Vol. 528, pp. (6469-6477).

Asadi P., Faraji G., Masoumi A. and Besharati Givi M. K. (2011). Experimental Investigation of Magnesium-Base Nanocomposite Produced by Friction Stir Processing: Effects of Particle Types and Number of Friction Stir Processing Passes, Metallurgical and Materials Transaction A, Vol. 42A, pp. (2820-2832).

Asadi P., Besharati Givi M. K., Parvin N., Araei A. Taherishargh M. and S. Tutunchilar, (2012). On the role of cooling and tool rotational direction on microstructure and mechanical properties of friction stir processed AZ91, International Journal of Advanced Manufacturing Technology, DOI 10.1007/s00170-012-3971-0.

ASM (1990) Metals Handbook, ASM International, Materials Park, Ohio

ASM (1993) Welding Brazing and Soldering, ASM International, Materials Park, Ohio

Berlin A. (2011). Magnetic Pulse Welding of Mg Sheet, MSC Thesis, Waterloo, Ontario, Canada. 
Berlin A., Nguyen T.C., Worswick M.J. and Zhou Y. (2011). Metallurgical analysis of magnetic pulse welds of AZ31 magnesium alloy, Science and Technology of Welding and Joining, Vol. 16, pp. (728).

Busk, R. S. (1987). Magnesium Products Design, Marcel Dekker Inc., ISBN, NewYork.

Cao X., Jahazi M., Immarigeon J. P. and Wallace W. (2006). A review of laser welding techniques for magnesium alloys, Journal of Materials Processing Technology, Vol. 171, pp. (188-204).

Cao X., Xiao M., Jahazi M. and Immarigeon J. -P. (2005). Continuous Wave ND:YAG Laser Welding of Sand-Cast ZE41A-T5 Magnesium Alloys, Materials and Manufacturing Processes, Vol. 20, pp. (987-1004).

Chi C. T. and Chao C. G. (2007). Characterization on electron beam welds and parameters for AZ31B-F extrusive plates, Journal of Materials Processing Technology, Vol. 182, pp. (369-373).

Chi C. T., Chao C. G., Liu T. F. and Wang C. C. (2006). A study of weldability and fracture modes in electron beam weldments of AZ series magnesium alloys, Materials Science and Engineering A, Vol. 435-436, pp. (672-680)

Czerwinski F. (2010). Welding and joining of magnesium alloys, In: Magnesium Alloys - Design, Processing and Properties, chapter 21, pp. (469-490).

Dhahri M., Masse J. E., Mathieu J. F., Barreau G. and Autric M. (2000). $\mathrm{CO}_{2}$ laser welding of magnesium alloys, X. Chen, T. Fujioka, A. Matsunawa (Eds.), Proceedings of the SPIE: High-Power Lasers in Manufacturing, Vol. 3888, 2000, pp. (725-732).

Dhahri M., Masse J. E., Mathieu J. F., Barreau G. and Autric M. (2001a) Laser weldability of WE43 magnesium alloy for aeronautic industry, Proceedings of the Third LANE2001: Laser Assisted Net Shape Engineering 3, Erlangen, 28-31 August 2001.

Dhahri M., Masse J. E., Mathieu J. F., Barreau G. and Autric M. (2001b). Laser welding of AZ91 and WE43 magnesium alloys for automotive and aerospace industries, Advance Engineering Materials, Vol. 3, No. 7, pp. (504-507).

Dilthey U., Haferkamp H., Niemeyer M. and Trager G. (1998). Laser and EB welding of magnesium alloys, American Institute of Welding, IIW Document No. IV-701-98.

Gilmore C. J., Dunfold D. V. and Parteidge P. G. (1991). Journal of Materials Science, Vol. 26, pp. (3119-3124).

Haferkamp H., Bach Fr. -W., Burmester I., Kreutzburg K. and Niemeyer M. (1996). Nd:YAG laser beam welding of magnesium constructions, Proceedings of the Third International Magnesium Conference, UMIST, Manchester, UK, 10-12 April 1996.

Haferkamp H., Goede M., Bormann A. and Cordini P. (2001). Laser beam welding of magnesium alloys-new possibilities using filler wire and arc welding, Net Shape Engineering, Vol. 3, pp. (333-338).

Haferkamp H., Niemeyer M., Dilthey U. and Trager G. (2000). Laser and electron beam welding of magnesium materials, Weld. Cutt., Vol. 52, No. 8, PP. (178-180).

Haferkamp H., Niemeyer M., Schmid C., Kaese V. and Cordini P. (2000). Laser welding of magnesium alloys-cooling conditions and resulting metallurgical properties magnesium 2000, Second International Conference On Magnesium Science and Technology, Dead Sea, Israel, 22-24 February 2000. 
Hwang I. S., Kim D. C. and Kang M. J. (2011). Inverter DC resistance spot welding of magnesium alloy AZ31, Materials Manufacturing and Processing, Vol. 48, No. 2, pp. (112117).

Hwang I. S., Yoon H. J., Kang M. J. and Kim D. C. (2010). Weldability of 440 MPa galvanized steel with inverter DC resistance spot welding process, Journal of Achievements in Materials and Manufacturing Engineering, Vol. 42, No. 1, pp. (37-44).

Kulekci, M. K. (2008). Magnesium and its alloys applications in automotive industry, International Journal of Advanced Manufacturing Technology, Vol. 39, pp. (851-865), ISSN.

Kore S. D., Imbert J., Worswick M. J. and Zhou Y. (2009). Electromagnetic impact welding of $\mathrm{Mg}$ to $\mathrm{Al}$ sheets, Science and Technology of Welding and Joining, Vol. 14, pp. (549).

Kou S. (2003). Welding Metallurgy (second edition), John Wiley \& Sons, Inc, 0-471-43491-4, Hoboken, New Jersey.

Lathabai S., Barton K. J. and Harris D. (2003). Welding and weldability of AZ31B by gas tungsten arc and laser beam welding processes, Magnesium Technology, Vol. 157.

Lehner C., Reinhart G. and Schaller L. (1999). Welding of die cast magnesium alloys for production, Journal of Laser Applications, Vol. 11, No. 5, pp. (206-210).

Leong K. H. (1998). Laser beam welding of AZ31B-H24 magnesium alloy, Proceedings of Laser Institute of America, ICALEO' 98 Conference, Orlando, FL, USA, 1998.

Liu L. and Xie L. (2007). Adhesive bonding between Mg alloys and polypropylene, Materials Technology: Advanced Performance Materials, Vol. 22, No. 2, pp. (76-80).

Liu L., Wang J. and Song G. (2004). Hybrid laser-TIG welding, laser beam welding and gas tungsten arc welding of AZ31B magnesium alloy, Materials Science and Engineering A, Vol. 381, pp. (129-133).

Luo Y., You G., Ye H. and Liu J. (2010). Simulation on welding thermal effect of AZ61 magnesium alloy based on three-dimensional modeling of vacuum electron beam welding heat source, Vacuum, Vol. 84, pp. (890-895).

Marya M. and Edwards G. R. (2000). The laser welding of magnesium alloy AZ91, Welding World, Vol. 44, No. 2, pp. (31-37).

Marya M. and Edwards G. R. (2001). Factors Controlling the Magnesium Weld Morphology in Deep Penetration Welding by a CO2 Laser, Journal of Materials Engineering and Performance, Vol. 10, No. 4, pp. (35).

Marya M. and Edwards G. R. (2002). Chloride contribution in flux-assisted GTA welding of magnesium alloys, Welding Journal, Vol. 12, pp. (291-298).

Marya M. and Edwards G. R. (2002). Influence of laser beam variable on AZ91D weld fusion zone microstructure, Science and Technology of Welding and Joining, Vol. 7, No. 5, pp. (286-293).

Marya M., Olson D. L. and Edwards G. R. (2000). Welding of magnesium alloys for transportation applications, Proceedings from Materials Solution '00 on Joining of Advanced and Specialty Materials, ISBN, St. Louis, Missouri, 9-11 October 2000.

Mishra R. S. and Ma Z. Y. (2005). Friction stir welding and processing, Materials Science and Engineering R, Vol. 50, pp. (1-78). 
Mordike B. L. and Ebert T. (2001). Magnesium: properties-applications-potential, Materials Science and Engineering A, Vol. 302, pp. (37-45).

Munitz A., Cotler C., Stern A. and Kohn G. (2001). Mechanical properties and microstructure of gas tungsten arc welded magnesium AZ91D plates, Materials Science and Engineering A, Vol. 302, pp. (68-73).

Oates W. R. (1996). Welding Hand book (eighth edition), American Welding Society, Miami, Florida.

Pastor M., Zhao H. and DebRoy T. (2000). Continuous wave Nd:yttrium-aluminium-garnet laser welding of AM60B magnesium alloys, Journal of Laser Applications, Vol. 12, No. 3, pp. (91-100).

Powers D. E. and Laflamme G. R. (1992). Welding Journal, pp. (47-52).

Shi H., Qiu R., Zhu J., Zhang K., Yu H. and Ding G. (2010). Effects of welding parameters on the characteristics of magnesium alloy joint welded by resistance spot welding with cover plates, Materials and Design, Vol. 31, pp. (4853-4857).

Somekawa H., Watanabe H. and Higashi K. (2003). The Grain Size Dependence on Diffusion Bonding Behavior in Superplastic Mg Alloys, Materials Transactions, Vol. 44, No. 4 pp. (496-503).

Stolbov V. I., El'tsov V. V., Oleinik I. A. and Matyagin V. F. (1990). Effect of the nature of thermal processes on cracking in repair welding components of magnesium alloys, Svarochnoe Proizvodstvo, Vol. 37, No. 5, pp. (29-31).

Suhuddin U. F. H. R., Mironov S., Sato Y. S., Kokawa H. and Lee C. -W. (2009). Grain structure evolution during friction-stir welding of AZ31 magnesium alloy, Acta Materialia, Vol. 57, pp. (5406-5418).

Wang Z., Gao M., Tang H. and Zeng X. (2011). Characterization of AZ31B wrought magnesium alloy joints welded by high power fiber laser, Materials Characterization, Vol. 62, pp. $(943-951)$.

Xiaoa L., Liua L., Chenb D. L., Esmaeili S. and Zhou Y. (2011). Resistance spot weld fatigue behavior and dislocation substructures in two different heats of AZ31 magnesium alloy, Materials Science and Engineering A, Vol. 529, pp. (81-87).

Yin Y. H., Sun N., North T. H. and Hu S. S. (2010). Microstructures and mechanical properties in dissimilar AZ91/AZ31 spot welds, Materials Characterization, Vol. 61, No. 10, pp. (1018-1028).

Yong Y., Da-tong Z., Cheng Q. and Wen Z. (2010). Dissimilar friction stir welding between 5052 aluminum alloy and AZ31 magnesium alloy, Transition of Nonferrous Metal Society, China, Vol. 20. pp. (619-623).

Yu L., Nakata K., Yamamoto N. and Liao J. (2009). Texture and its effect on mechanical properties in fiber laser weld of a fine-grained $\mathrm{Mg}$ alloy, Materilas Letters, Vol. 63, pp. (870-872).

Zhang D., Suzuki M. and Maruyama k. (2005). Microstructural evolution of a heat-resistant magnesium alloy due to friction stir welding, Scripta Materialia, Vol. 52, pp. )899903). 
Zhang Z. D., Liu L. M., Shen Y. and Wang L. (2008). Mechanical properties and microstructures of a magnesium alloy gas tungsten arc welded with a cadmium chloride flux, Materials Characterization, Vol. 59, pp. (40 - 46).

Zhao H. and Debroy T. (2001). Pore formation during laser beam welding of die cast magnesium alloy AM60B-mechanism and remedy, Welding Journal, Vol. 80, No. 8, pp. (204-210).

Zhu J., Li L. and Liu Z. (2005). CO2 and diode laser welding of AZ31 magnesium alloy, Applied Surface Science, Vol. 247, pp. (300-306). 